\title{
What Caused Racial Disparities in Particulate Exposure to Fall? New Evidence from the Clean Air Act and Satellite-Based Measures of Air Quality
}

\author{
by
}

\author{
Janet Currie \\ Princeton University \\ John Voorheis \\ U.S. Census Bureau
}

Reed Walker

UC Berkeley

\section{CES 20-02 January, 2020}

The research program of the Center for Economic Studies (CES) produces a wide range of economic analyses to improve the statistical programs of the U.S. Census Bureau. Many of these analyses take the form of CES research papers. The papers have not undergone the review accorded Census Bureau publications and no endorsement should be inferred. Any opinions and conclusions expressed herein are those of the author(s) and do not necessarily represent the views of the U.S. Census Bureau. All results have been reviewed to ensure that no confidential information is disclosed. Republication in whole or part must be cleared with the authors.

To obtain information about the series, see www.census.gov/ces or contact Christopher Goetz, Editor, Discussion Papers, U.S. Census Bureau, Center for Economic Studies 5K038E, 4600 Silver Hill Road, Washington, DC 20233, CES.Working.Papers@census.gov. To subscribe to the series, please click here. 


\begin{abstract}
Racial differences in exposure to ambient air pollution have declined significantly in the United States over the past 20 years. This project links restricted-access Census Bureau microdata to newly available, spatially continuous high resolution measures of ambient particulate pollution (PM2.5) to examine the underlying causes and consequences of differences in black-white pollution exposures. We begin by decomposing differences in pollution exposure into components explained by observable population characteristics (e.g., income) versus those that remain unexplained. We then use quantile regression methods to show that a significant portion of the "unexplained" convergence in black-white pollution exposure can be attributed to differential impacts of the Clean Air Act (CAA) in non-Hispanic African American and non-Hispanic white communities. Areas with larger black populations saw greater CAA-related declines in PM2.5 exposure. We show that the CAA has been the single largest contributor to racial convergence in PM2.5 pollution exposure in the U.S. since 2000 accounting for over 60 percent of the reduction.
\end{abstract}

\footnotetext{
* This paper is released to inform interested parties of research and to encourage discussion. The views expressed are those of the authors and not necessarily those of the U.S. Census Bureau. All results have been reviewed to ensure that no confidential information is disclosed, release authorization numbers CBDRB-FY19-CMS-7029, CBDRBFY19-CMS-7227, CBDRB-FY19-CMS-7328 and CBDRB-FY19-CMS-7735. We would like to thank Abhay Aneja, Spencer Banzhaf, David Card, Conrad Miller, Jessie Shapiro, Joe Shapiro, and seminar participants at the Chicago Federal Reserve, the Environmental Defense Fund, Gothenberg University, LISER, Rotterdam University, Stanford University, Tufts, UC Berkeley, the University of Chicago, the University of Hawaii, and the University of Illinois for helpful comments. Ellen Lin and Matthew Tarduno provided exceptionally helpful research assistance.
} 


\section{Introduction}

Landmark studies in the 1980s (see for example Office (1983); Chavis and Lee (1987)) demonstrated that low income and/or racial minorities in the U.S. are disproportionately exposed to environmental burdens. This issue had become so politically important by the 1990s that President Clinton issued Executive Order 12898 in 1994, which ordered the U.S. Environmental Protection Agency (EPA) to explicitly study this "environmental justice" issue. ${ }^{1}$ However, despite its large volume, the existing evidence about racial disparities in pollution exposure is largely piecemeal and indirect.

The evidence is piecemeal because pollution monitoring networks are sparse. For example, fewer than 20 percent of U.S. counties contain a regulatory grade device capable of monitoring small particulates (Fowlie, Rubin, and Walker, 2019). ${ }^{2}$ The evidence remains somewhat indirect because researchers have been forced to use proxies for potential exposure such as distance to a polluting facility. ${ }^{3}$ Distance to a facility is a crude substitute for ambient air pollution exposure, both for reasons related to air transport and because mobile sources of pollution are also important contributors to local air quality. Hence, while we know that there are racial differences in the proximity to toxic facilities and hazardous waste sites, it is less clear how these differences translate to differences in measured exposures. Moreover, we know very little about why racial gaps in pollution exposure may have changed over time.

This paper addresses these gaps in our knowledge using newly available national data on ambient particulate matter (PM2.5) exposure from 2000 to 2015. Advances in remote sensing technology combined with machine learning prediction tools have allowed researchers to combine data from satellite imagery, pollution monitors, land use characteristics, chemical air transport models to generate fine-grained (1km grid) measures of ambient air pollution levels for the entire United States (Di, Kloog, Koutrakis, Lyapustin, Wang, and Schwartz, 2016; Van Donkelaar, Martin, Brauer, Hsu, Kahn, Levy, Lyapustin, Sayer, and Winker, 2016). We merge these granular pollution data to individual survey responses from restricted use versions of the

\footnotetext{
${ }^{1}$ Banzhaf, Ma, and Timmins (2019) have an excellent recent review of the economics literature on this subject.

${ }^{2}$ Similarly, Hsiang, Oliva, and Walker (2019) point out that out of 3144 counties, only 1289 have monitors for any "criteria" air pollutant (i.e. pollutants regulated under the Clean Air Act) at any point between 1990-2015.

${ }^{3}$ For example, several case studies on residential proximity to polluting industrial facilities find that racial and ethnicity minority groups and/or lower socioeconomic status groups experienced closer average proximity to industrial facilities compared with other groups, and that this pattern persists over time (e.g., Abel and White (2011) who study Seattle, 1990 to 2007 ; Hipp and Lakon (2010) who study southern California, 1990 to 2000; Pais, Crowder, and Downey (2013) who examine a national cohort from 1990 to 2007). There are challenges to drawing causal inferences from this literature ranging from from ecological fallacy (Depro, Timmins, and O'Neil, 2015; Hsiang, Oliva, and Walker, 2019) to problems associated with assuming that people in geographic areas that do not contain hazards are not exposed to pollutants, even when the hazards in question may lie close to geographic boundaries (Banzhaf, Ma, and Timmins, 2019; Mohai and Saha, 2006; Mohai, Pellow, and Roberts, 2009).
} 
2000 Census and the 2001-2015 American Community Survey (ACS) at the Census Block level.

The paper proceeds in four parts. We first use these data to document gaps in ambient exposure to PM2.5 between non-Hispanic African Americans and non-Hispanic whites and to show how these gaps changed over time from 2000 to $2015 .{ }^{4}$ Next, we explore whether these cross-sectional gaps in pollution exposure can be explained by differences in individual and/or neighborhood characteristics, as reported in the 2000 Census or ACS. Third, we explore the extent to which changes in relative mobility versus relative improvements in neighborhood air quality have contributed to the changes in gaps in pollution exposure over this time period. Lastly, we use quantile regression methods proposed by Firpo, Fortin, and Lemieux (2009) to explore the extent to which the spatially targeted nature of the Clean Air Act, and the associated introduction of the PM2.5 National Ambient Air Quality Standards (NAAQS), has affected different parts of the national pollution distribution and, in turn, the observed black-white pollution gap in the United States.

The analysis confirms that African Americans tend to live in the most polluted areas nationally. However, this black-white gap in mean pollution exposure has closed substantially since the turn of the century. The mean gap in pollution exposure has converged from $1.5 \mu \mathrm{g} / \mathrm{m}^{3}$ in 2000 to only $0.5 \mu \mathrm{g} / \mathrm{m}^{3}$ in 2015 . This convergence alone could potentially explain $7 \%$ of the improvement in relative life expectancy between blacks/whites over this time period. ${ }^{5}$ We then explore the underlying cross-sectional correlates of the observed pollution gaps by leveraging the individual microdata in the Census and ACS. We begin by comparing the unconditional mean gap in pollution exposure between African Americans and non-Hispanic whites to the conditional mean pollution gap after controlling for individual characteristics (e.g., income, education, household structure). We also examine whether individual characteristics are able to explain gaps in exposure at other quantiles of the pollution distribution, in the spirit of DiNardo, Fortin, and Lemieux (1996). We find that virtually none of the racial difference in exposure can be explained by differences in individual or household-level characteristics such as income, suggesting that only a small portion of the observed convergence in pollution levels can be explained by relative changes in these characteristics over time.

Mechanically, there are two remaining ways this narrowing of the pollution gap could have occurred: Areas that were disproportionately African American may have become cleaner faster than other areas; or relative population shares could have shifted in ways that benefited African Americans relative to the non-Hispanic white population. We use a simple decomposition to show that relative mobility differences

\footnotetext{
${ }^{4}$ Note that we will use "black" and "African American" interchangeably with "non-Hispanic African American" throughout the text (likewise for "white" and "non-Hispanic white")

${ }^{5}$ See Section 2 below for a more complete description of this calculation.
} 
or changes in black-white population shares are not able to explain the observed convergence in pollution exposure. While the white population has been gradually shifting to more urban and hence more polluted areas, this phenomenon explains very little of the observed black-white convergence in pollution exposure when compared to the significant air quality improvements in the average black neighborhood over this time period.

The convergence in the racial gap in pollution exposure between 2000 and 2015 can be entirely accounted for by the fact that areas that were disproportionately African American showed the greatest improvement in air quality over this time period. Why is this the case? We show that much of this improvement is driven by the introduction of the PM2.5 National Ambient Air Quality Standards, which disproportionately improved air quality in newly regulated areas - areas with higher concentrations of African Americans. More specifically, we use unconditional quantile regression (Firpo, Fortin, and Lemieux, 2009) in a difference-indifferences setting to show how the introduction of the PM2.5 NAAQS affected different quantiles of the national pollution distribution. We then combine these quantile regression estimates with the black and white population shares in the respective pollution quantiles to calculate that over 60 percent of the observed convergence in mean PM2.5 differences between blacks and whites over this time period can be traced back to the spatially targeted nature of the CAA regulations.

A small but growing literature in economics and other social sciences has begun using remote sensing data to measure the distribution of environmental hazards (see e.g., Fowlie, Rubin, and Walker (2019) for a recent overview and application). A subset of this literature studies environmental inequality by merging remote-sensing data to Census tract or Census block group demographic data. For example, Clark, Millet, and Marshall $(2014,2017)$ examine racial differences in exposure to $\mathrm{NO}_{2}$ using 2006 Census Block-Group $\mathrm{NO}_{2}$ measurements linked to the 2000 Decennial Census data, and Voorheis et al. (2017) examine differences in exposure to $\mathrm{NO}_{2}$ and PM2.5 using satellite data combined with tract-level aggregates from the American Community Survey. ${ }^{6}$

\footnotetext{
${ }^{6}$ Relatively few U.S. studies have explored temporal trends in racial gaps in ambient air pollution or transportation-related air pollution. Brajer and Hall (2005), studied ozone and coarse particulate matter in southern California from 1990 to 1999 , and found that on average, as air pollution decreased over time, Asians and Hispanics experienced larger reductions in ozone concentrations but smaller reductions in coarse particulate matter concentrations, compared with other groups. Kravitz-Wirtz, Crowder, Hajat, and Sass (2016), studied nitrogen dioxide and particulate matter exposures in the United States for a cohort of 9,000 families from 1990 to 2009, and found that though exposures decreased over time, they remained higher for blacks and Hispanics than for whites. Ard (2015) look at racial trends in exposures to toxic releases from 1995 to 2004 , using data on releases of 415 chemicals from 17,604 facilities reporting in the Toxic Release Inventory. They find that potential exposure to toxics declined for all, but that African Americans are still more exposed than Whites or Hispanics, even conditional on income and education. Voorheis et al. (2017) uses administrative records and satellite data to compare within-person changes in pollution exposure between blacks and whites.
} 
This is the first paper, to our knowledge, that links nationally representative, individual-level survey data to a national surface grid of PM2.5 pollution measurements to explore cross-sectional differences and trends in environmental inequality between racial groups. Moreover, we are not aware of any papers that have explored the causal determinants of narrowing pollution gaps between racial groups over time. Our data not only has useful features from a measurement perspective, allowing for higher quality measurement of the distribution of pollution exposure than has been possible before, but it also allows us to answer questions that cannot be addressed with public-use Census data. For example, the restricted versions of the Decennial Census and ACS data, which provide block-level geographic information, allow us to distinguish between differences in pollution exposure that can be explained by differences in individual characteristics (e.g., income) or differences in neighborhood characteristics (e.g., racial mix). While these findings are descriptive, we are able to explore, for the first time, how much variation in pollution exposure might plausibly be explained by individual endowments, and how much may instead be explained by aggregate, neighborhood-level characteristics. Lastly, the spatially continuous PM2.5 measurements allow us to create these statistics and perform these decompositions for the entire continental U.S., as opposed to focusing on a single city or on communities that are proximate to a toxic plant or a pollution monitor.

The second contribution of this paper is to explore the distributional impacts of environmental policy and the Clean Air Act more specifically. In doing so we are able to examine the degree to which these distributional impacts may account for the aggregate changes in environmental inequality, and the concomitant effects on health therein. While a substantial literature examines the average effects of the Clean Air Act on pollution exposure and the harms that it causes (e.g., Chay and Greenstone (2003); Isen, RossinSlater, and Walker (2017)), we know of no other work that explores the impact of the Clean Air Act on different empirical moments of the nationwide pollution distribution. For example, we are able to address the question of how much the CAA NAAQS have compressed the national pollution distribution, and to ask which quantiles show the largest effects? The advent of unconditional quantile regression and related methods (Firpo, Fortin, and Lemieux, 2009), combined with the new availability of spatially continuous PM2.5 measurements and detailed demographic data, make such analysis possible.

In summary, our study uses high-resolution PM2.5 data and restricted-access Census Bureau data to measure gaps in racial exposure to pollution for a nationally representative sample of the U.S. population. Our main innovation is to explore the reasons why the racial gap has declined by asking what part of the decline can be attributed to convergence in the individual and household-level characteristics of African 
American and other households; how much can be explained by the relative mobility of different racial groups (e.g., blacks moving away from polluted areas); how much can be explained by more rapid cleanup of historically black neighborhoods; and how much of the more rapid clean-up of historically black neighborhoods that we observe is due to the spatially targeted nature of the CAA.

The rest of the paper proceeds as follows. Section 2 introduces the linked Census and satellite derived pollution data and provides initial descriptive statistics on environmental inequality between racial groups. Section 3 explores whether these mean and quantile differences can be explained by differences in individual characteristics and changes to those characteristics over time. Section 4 tests for how the spatially targeted nature of the Clean Air Act affects the national distribution of PM2.5 exposure, and how these quantile changes map into the observed black-white gap in pollution exposure. Section 5 concludes.

\section{Data and Descriptive Statistics on Racial Gaps in Pollution Exposure}

Environmental science has seen a recent explosion of research in atmospheric science combining spatiallycontinuous satellite measurements of pollution correlates (e.g., aerosol optical depth) with other observable pollution correlates such as emissions inventories, chemical transport models, land use characteristics, and weather patterns (see e.g., Di, Kloog, Koutrakis, Lyapustin, Wang, and Schwartz (2016); Van Donkelaar, Martin, Brauer, Hsu, Kahn, Levy, Lyapustin, Sayer, and Winker (2016)). The basic idea is to build a predictive model of a pollutant of interest (e.g., PM2.5) by correlating in-situ EPA monitor data with the observable predictors of air pollution measures using modern model selection techniques (e.g., crossvalidated neural nets). Researchers then use these models to predict air pollution "out of sample" for the large segments of the United States without existing pollution monitors but with satellite measurements. We use data from Di, Kloog, Koutrakis, Lyapustin, Wang, and Schwartz (2016), who produce daily PM2.5 concentrations at a 0.01 degree by 0.01 degree resolution $(1 \mathrm{~km}$ by $1 \mathrm{~km}$ at the equator) for the contiguous U.S. from 2000-2015. ${ }^{7}$ We spatially intersect this gridded, raster data with Census block boundary files, which we use to merge the pollution data to the individual survey responses from the 2000 Census and 2001-2015 ACS. $^{8}$

It is important to note that these pollution data are estimates of ground-level pollution concentrations.

\footnotetext{
${ }^{7}$ We have replicated most of the results in this project using similar data from Van Donkelaar, Martin, Brauer, Hsu, Kahn, Levy, Lyapustin, Sayer, and Winker (2016), and the qualitative conclusions are very similar.

${ }^{8}$ Because Census block boundaries changed after the 2010 Census, we use the 2000 Census vintage block boundaries for the 2000 Census and ACS data through 2010, and then use the 2010 vintage boundaries afterwards.
} 
These estimates perform well — on average, they match the "ground truth" as measured by EPA monitors, with very high, in-sample measures of fit. However, there is some evidence that these satellite-derived measures may deviate from the ground truth at the tails of the pollution exposure distribution (Fowlie, Rubin, and Walker (2019)). Two of the most commonly used measures, in particular - Di, Kloog, Koutrakis, Lyapustin, Wang, and Schwartz (2016) and Van Donkelaar, Martin, Brauer, Hsu, Kahn, Levy, Lyapustin, Sayer, and Winker (2016) - are biased downward for high PM2.5 levels. It seems likely in our setting that these prediction errors will attenuate measured disparities since African Americans are disproportionately located in the most highly polluted places. We will proceed with our analyses treating the satellite data as if it were the truth, keeping in mind the caveat that our results may be a lower bound on true racial gaps in exposure.

We merge the pollution data with individual-level data from the 2000 Census long form (1 in 6 U.S. households) and from the 2001-2015 American Community Surveys using household Census block locations. Our primary comparisons focus on the non-Hispanic white and African American populations. We focus on gaps between African Americans and non-Hispanic whites because historically these have been the largest and most well-documented gaps. Additionally, there are potential measurement issues in studying differences between Hispanics and non-Hispanic whites over time. For example, studies which have linked individual responses to the 2000 and 2010 Decennial Censuses find evidence that Hispanic identity is more fluid over time than white or black racial identities (Liebler, Porter, Fernandez, Noon, and Ennis, 2017). Examination of disparities among Hispanics, non-Hispanic whites and non-Hispanic African-Americans is fruitful ground for future work, however.

Figure 1 plots mean pollution exposure for both the African American (dotted red line) and non-Hispanic white population (solid blue line) from 2000 to 2015. The observed black-white gap in mean pollution exposure is 1.6 micrograms per cubic meter $\left(\mu \mathrm{g} / \mathrm{m}^{3}\right)$ in 2000 , narrowing to $0.54 \mu \mathrm{g} / \mathrm{m}^{3}$ in 2015 . One way to interpret these differences is to translate the gaps into racial differences in life-expectancy through the lens of a PM2.5 concentration-mortality response function. Ebenstein et al. (2017) estimate that life expectancy is reduced by 0.98 years for each $10 \mu \mathrm{g} / \mathrm{m}^{3}$ increase in sustained exposure to PM2.5. Over this time period, the black-white gap in life expectancy fell from about 5 years to 3.5 years (Arias and Xu, 2019). Thus, the observed $1 \mu \mathrm{g} / \mathrm{m}^{3}$ improvement in the black-white pollution gap could potentially explain $7 \%$ of this improvement in the black-white mortality gap. ${ }^{9}$

\footnotetext{
${ }^{9}$ This is calculated as $0.98^{*}(1 / 10) / 1.5$ years. Note that the Arias and $\mathrm{Xu}(2019)$ only reports black-white gaps in life
} 
While Figure 1 presents the mean black-white gap over time, the data also allow us to explore the entire distribution of pollution exposure for each race group and how these distributions have changed over time. Figure 2 plots the pollution densities, separately for the African American and non-Hispanic white population in both 2000 and 2015. ${ }^{10}$ When comparing the x-axis of both the 2000 and 2015 figures, it becomes clear that PM2.5 pollution levels have fallen dramatically for both groups. For example, in 2000, the bulk of both distributions lies above $10 \mu \mathrm{g} / \mathrm{m}^{3}$, while in 2015 the bulk of both distributions lies below that threshold. The other salient feature of these densities is that most of the improvements for blacks relative to whites between 2000 and 2015 come from compressing the upper portion of the pollution distribution, a point to which we will return.

\section{Decomposing Differences in Pollution Exposure}

What explains the observed differences in pollution exposure? Perhaps lower income individuals live in more polluted places, and differences disappear or are greatly attenuated when we condition on income. Or perhaps differences in education and/or knowledge about the potential harms of PM2.5 exposure lead to observed differences in pollution exposure? The Census Bureau demographic data allow us to explore the cross-sectional and time-series differences in pollution exposure between racial groups. The demographic data also allow us to begin to explore the extent to which individual endowments can explain the observed differences and changes. Conditional on income differences, does the observed black-white gap in pollution exposure remain? We focus on the following individual-level characteristics measured in the Decennial Census long-form and ACS surveys: race, age, gender, income, education, number of children, and home ownership. We also explore the role of neighborhood characteristics in explaining pollution disparities, using Census tract characteristics constructed from the underlying microdata, including: the population share of African Americans in a tract, mean public assistance income, the teen pregnancy rate, average years of schooling, the population share living in single family residences, and the home ownership rate. Appendix Table B1 presents summary statistics of these variables, separately for non-Hispanic white and African American individuals in our sample.

expectancy as far back as 2006. The 2000-2015 change in the black-white life expectancy was likely larger than 1.5, reducing the percentage contribution of PM2.5 in explaining this improvement.

${ }^{10}$ Due to Census disclosure avoidance review guidelines, we trim the upper 97th and lower 3rd percentiles of each pollution distribution. 


\subsection{Conditional versus Unconditional Differences in Pollution Exposure}

Figure 1 shows a large gap in pollution exposure in 2000, which fell considerably over the next fifteen years. As a first step towards understanding the reasons for this declining gap, we start by asking whether crosssectional differences in exposure in any given year can be explained by differences in individual characteristics from the Decennial Census and ACS. One natural way to do this is to compare the conditional mean differences in pollution exposure between racial groups to the unconditional mean differences using the following linear regression model:

$$
P_{i}=\gamma 1\left[\text { African } \operatorname{American}_{i}\right]+X^{\prime} \beta+\epsilon_{i}
$$

where pollution for individual $i$ is regressed on an indicator for whether or not the individual is African American, controlling for individual demographic characteristics in the vector $(X)$. Specifically, we control for individual income, age, education, number of children, gender, and an indicator for homeownership. Regressions are weighted using 2000 long form and ACS weights, and inference is conducted with clusterrobust standard errors, clustering by commuting zone. Figure 3a plots the coefficient $\gamma$ and associated confidence intervals from 15 separate regressions, one per year, representing the conditional mean differences in black-white pollution exposure over time. Figure $3 \mathrm{~b}$ compares these estimates to the unconditional mean differences in pollution exposure over time. The lines look almost identical. This similarity implies that differences in individual characteristics, such as income, explain almost none of the cross-sectional differences in pollution exposure between African Americans and non-Hispanic whites. This conclusion is striking considering that African American households have mean household income more than $\$ 15,000$ lower than non-Hispanic whites (see Appendix Table B1). These differences in income and other characteristics explain almost none of the observed differences in pollution exposure. Appendix A.1 formally decomposes these cross-sectional differences in mean pollution exposure using methods pioneered by Oaxaca (1973) and Blinder (1973). Observable differences in individual and household characteristics are able to explain at most 8 percent of the gap in mean differences in any given year.

Gaps in pollution exposure are also found at different points within the income distribution. Table 1 presents the results from 10 separate estimates of $\gamma$ from equation (1), where we stratify the data by income quintiles in both 2000 and 2015. At each quintile, the conditional gap remains similar to the unconditional gap in a given year. Differences in individual characteristics do little to explain the mean differences in 
pollution exposure within these income categories.

Equation (1) and the Oaxaca-Blinder exercise in Appendix A.1 are well-suited for decomposing differences in mean black-white pollution exposure. However, Figure 2 suggests there exist additional racial differences at different quantiles of the pollution distribution. A natural question to ask is whether differences in individual or household characteristics are able to explain differences in pollution exposure at other parts of the pollution distribution. DiNardo, Fortin, and Lemieux (1996) provide a straightforward semi-parametric approach to answering this question. The basic idea is to estimate what the entire distribution of African American pollution exposure would look like if African Americans had the same observable characteristics as non-Hispanic whites. In practice, this amounts to constructing a weighting function that is then used to re-weight a kernel density estimate of the African American pollution distribution to provide the relevant counterfactual distribution African Americans would have experienced given the same characteristics as non-Hispanic whites. This weighting function boils down to estimating a conditional probability of being a non-Hispanic white individual based on observable, demographic characteristics via a probit regression. This conditional probability is then used, along with the unconditional probabilities of being white/black in our sample to reweight the African American kernel density in a given year.

The results from this exercise are presented in Figure 4. Figure 4a presents estimates of the counterfactual pollution distribution in 2000, and Figure 4b presents estimates of the counterfactual pollution distribution in 2015. In both cases, the counterfactual density looks very similar to the actual density, again suggesting that individual characteristics are able to explain little of the observed pollution gap throughout the distribution. Appendix A.1 and Appendix Table B3 use methods proposed by Firpo, Fortin, and Lemieux (2009) to formally decompose the 10th, 50th, and 90th percentiles of the pollution distribution into the parts that can be explained by observable covariates versus the part that remains unexplained. Once again, we find that little can be explained by observable individual-level characteristics from Census Bureau data.

\subsection{Controlling for neighborhood characteristics}

While individual and/or household characteristics explain little of the black-white pollution gap, there is substantial racial segregation into different areas within and across communities (Logan and Parman, 2017). Are the differences in characteristics of black and white neighborhoods able to explain these gaps in exposure? Panel 2 of Appendix Table B1 presents mean Census tract characteristics, separately for non-Hispanic whites and African Americans. African Americans not only have different individual and household-level 
characteristics on average, but they also tend to be concentrated in Census tracts with a high percentage of other African Americans and with many relatively disadvantaged neighbors. Note that there is nothing mechanical about this - if neighborhoods were perfectly integrated in terms of race and socioeconomic status, then everyone would live in a similar Census tract regardless of their own characteristics. Hence, we can control for characteristics of neighborhoods or Census tracts as well as characteristics of individuals in equation (1) in order to explore whether black-white differences in neighborhood characteristics (conditional on individual characteristics) are able to explain some of the observed differences in PM2.5 exposure.

Figure 5 shows the results of adding neighborhood characteristics to equation (1), and Appendix Table B4 presents the associated Oaxaca-Blinder decomposition. Specifically, we add census-tract level measures of percent African American, mean public assistance income, the teen pregnancy rate, years of schooling, the share living in single family residences, and the home ownership rate to equation (1). Figure 5, which plots year-by-year estimates of $\gamma$, looks substantially different than Figure 3a. Namely, the conditional gap in pollution exposure between African Americans and non-Hispanic whites is entirely explained by differences in neighborhood characteristics. Appendix Table B4 explores this result in greater detail. The table shows the fraction of the gap that is "explained" and "unexplained" by each variable separately, as well as the combined effect of these neighborhood characteristics. As one can see from the "Explained" panel of Appendix Table B4, black-white differences in neighborhood characteristics explain the entire gap in pollution exposure and more. More specifically, the mean difference in the African American proportion of the population in a black vs. a white person's Census tract explains $140 \%$ of the overall PM2.5 pollution gap in 2000. In 2015, the mean difference in this single neighborhood covariate explained $135 \%$ of the observed pollution gap. There are also substantial differences in the returns or responsiveness of individuals to differences in neighborhood characteristics (i.e. Panel B); a one-year increase in the mean Census tract education translates into substantially less pollution exposure for whites than it does for blacks in our sample, which is reflected in the relatively large difference in estimated "slopes" on the "Tract Years of Schooling" variable in Panel $\mathrm{B}$.

The fact that African Americans live in different neighborhoods than non-Hispanic whites on average explains virtually all of the gap in pollution exposure but also raises further questions. Does the shrinking of the racial gap in pollution exposure come from disproportionate improvements in air quality in neighborhoods that have higher proportions of African Americans, or is the improvement due to the relative movement of African Americans away from dirty neighborhoods towards cleaner ones? We next present an additional 
decomposition which attempts to shed light on these questions.

\subsection{People versus Places: Understanding How Relative Mobility Has Affected Pollu- tion Disparities}

One straightforward way to understand the role of mobility in contributing to the convergence in pollution exposure between blacks and whites is to consider what the pollution gap in 2015 would have been if we fixed individuals in their 2000 locations but let pollution in their respective Census block change to its 2015 level. ${ }^{11}$ Table 2 presents results from this type of counterfactual exercise. Columns (1) and (2) present the actual pollution levels experienced by blacks and whites in 2000 and 2015, and the associated gap (row 3) and change in gap (row 4). Column (3) of Table 2 presents the results from a counterfactual exercise, where we simulate what the gap (and change in gap) would have been in 2015 if people's locations had been held fixed. The last row of Column (3) tells us that the change in the pollution gap would have been smaller if individuals were unable to move between 2000 and 2015. Relative differences in mobility between blacks and whites over this time period contributed to additional convergence in the pollution gap. African Americans moved to relatively cleaner places between 200 and 2015, and the opposite is true for non-Hispanic Whites. This pattern is consistent with recent findings in urban economics which show that, after decades of suburbanization, the urban population became whiter and more college-educated in most large U.S. cities after 2000 (Baum-Snow and Hartley, 2019; Couture and Handbury, 2017), and similarly, suburbs have become more diverse. The shift in white population shares towards urban centers contributes to higher levels of average pollution exposure among whites than they would have experienced had they remained in predominantly suburban locations.

One can decompose the overall shrinkage in the black-white exposure gap into the part which can be explained by mobility versus the part which remains unexplained. If populations were fixed in their 2000 locations, the gain would have been $0.89 \mu \mathrm{g} / \mathrm{m}^{3}$ versus $1.02 \mu \mathrm{g} / \mathrm{m}^{3}$. Thus, only $12.7 \%$ of the improvement in the exposure gap stems from relative mobility differences over this time period, leaving the rest to be explained by a greater improvement in pollution in disproportionately African American areas.

Appendix A.3 presents additional results that explore the year-by-year changes in black-white population shares and pollution exposure in ways that shed further light on the role of mobility in explaining pollution

\footnotetext{
${ }^{11}$ For this counterfactual exercise, we use the public-use $100 \%$ count population data from the 2000 Decennial Census at the Census block level. We merge these data to the 2000 and 2015 Di, Kloog, Koutrakis, Lyapustin, Wang, and Schwartz (2016) data to calculate mean exposure gaps using block level population counts for non-Hispanic whites and African Americans.
} 
gaps. For example, the once strong negative assortative relationship between white population shares and pollution levels has weakened over time. Even so, the role of relative mobility differences remains small (certainly less than 15\%).

There is a separate question as to whether relative mobility is related to changes in air quality over this time period. Are non-Hispanic whites moving into the set of cities that have seen the largest improvements in air quality over this time period? It's possible that both non-Hispanic whites are moving into areas where air quality has dramatically improved and increasing their relative pollution exposure. Consider the case where an individual moves from the relatively less polluted suburbs towards the city center where air quality has improved; while this individual is moving to the urban center that has cleaned up, her new air quality exposure may remain above what her exposure would have been in the suburbs. We explore these issues in more detail in subsequent sections.

\section{The Clean Air Act and Relative Changes in Pollution Exposure}

Thus far, we have documented that a) the black-white gap in exposure to particulate matter has declined substantially since 2000, and b) neither individual characteristics nor residential mobility of individuals appears to fully explain why this gap has declined. Rather, it appears that the black-white gap in exposure has declined primarily because African American neighborhoods had greater improvements in air quality. But why did these particular neighborhoods experience improvements in air quality? We hypothesize that a major reason for the narrowing of the black-white gap in air quality is that changes in the enforcement of the Clean Air Act between 2000-2015 were more binding in predominantly black neighborhoods. We formally investigate this hypothesis below.

The CAA was first implemented in 1963, but the original legislation provided limited federal oversight of state efforts and did not lead to large improvements in air quality. In response, Congress enacted the Clean Air Act Amendments of 1970 and established the EPA, which vastly increased federal power to address air pollution. ${ }^{12}$ The CAA initially focused on common, dangerous, air pollutants known as "criteria air pollutants." Compliance was to be achieved through regulations governing both stationary sources (e.g., factories) and mobile sources (e.g., cars).

For stationary sources, the CAA created pollutant-specific national ambient air quality standards (NAAQS)

\footnotetext{
${ }^{12}$ Currie and Walker (2019) provide a more complete overview of the Clean Air Act and associated research by economists.
} 
that specify maximum allowable concentrations of criterion air pollutants. NAAQS were initially established for sulfur dioxide $\left(\mathrm{SO}_{2}\right)$, carbon monoxide $(\mathrm{CO})$, nitrogen dioxide $\left(\mathrm{NO}_{2}\right)$, lead, particulates (TSP), and eventually ozone $\left(\mathrm{O}_{3}\right)$. Stationary source regulations focus primarily on areas that are out of compliance with the NAAQS. Each year in July, the EPA determines the set of counties that are in violation or "nonattainment" of a particular NAAQS standard based on air pollution monitor measurements in those or nearby counties. The consequences of being a "nonattainment" area can be severe. State governments must develop a pollutant-specific plan, known as a State Implementation Plan, describing how areas will improve air quality and come into compliance. The EPA reviews these state plans. If a state fails to act or develop an inadequate plan, the EPA can withhold federal funding for the state air pollution control program, highway construction, and the construction of sewage treatment plants. The EPA can also ban permits for construction of major new and/or modified sources of a pollutant in communities that are out of compliance with NAAQS. In addition, the EPA can impose its own federal plan if it deems a state's plan inadequate. Thus, the CAA gives the EPA sweeping powers to take action to improve air quality, with or without state cooperation.

Since 1970, there have been two major amendments to the CAA, in 1977 and 1990, and hundreds of additional policies designed to respond to changing scientific consensus about both the harms from pollution and feasible compliance technologies. In 1997, the EPA tightened the NAAQS pertaining to ozone and particles further, regulating fine particles less than 2.5 micrometers in diameter (PM2.5) for the first time. The new standards were extremely controversial and were challenged in the courts for years, but ultimately the EPA prevailed, and the new standards were implemented in April 2005. The EPA revised the PM2.5 (24 hour) standard again in 2006, and the revision went into effect in 2009. However, since all counties which were in nonattainment of the annual PM2.5 standard in 2009 were also in nonattainment of the 24 hour standard, the 2009 designations do not appear to have caused additional new areas to be subject to NAAQS nonattainment regulations. We focus on the effects of mandated reductions in annual PM2.5 under the 1997 standards which finally began to be implemented in 2005.

To what extent is the cleanup of predominantly African American areas a result of the implementation of these new standards? We have seen that African Americans lived in more polluted places on average in 2000, and the initial impact of the CAA was therefore likely to be greatest in these places. Figure 6a shows the distribution of the African American and non-Hispanic white populations by vigintile of PM2.5 levels in 2000; the former were much more likely to live in the highest pollution deciles, while for whites the 
situation is reversed. Figure $6 \mathrm{~b}$ shows that it was predominantly counties in the highest PM2.5 deciles that were impacted by the enforcement of the standards in 2005. Hence, unless the initial impact of stronger regulation was undone by re-sorting of population shares, we would expect the regulations to close gaps between blacks and whites.

We begin by examining the effect of these new air quality standards on pollution exposure in a standard difference-in-difference, event-study design. To better mimic the way the regulations work in practice we adopt a slightly unconventional regression model when compared to the existing literature. Whenever a county exceeds the air quality standard based on a local monitoring station, the regulator decides whether nearby or adjacent counties could also have contributed to this violation. Thus, these nonattainment designations apply to "air regions" or groups of counties in the same local market, typically not a single county. We approximate these air region definitions using county-aggregates in the form of commuting zones $(\mathrm{CZs})$ or local labor markets. ${ }^{13}$ Figure 7 shows that, once the standards went into effect in 2005,62 commuting zones, consisting of 250 counties in 20 states, were designated as nonattainment areas.

We estimate an event study model of the following form:

$$
P_{i c t}=\sum_{t=2000}^{2015} \beta_{t}\left(1\left[\text { Nonattain }_{c}\right] \times 1\left[\text { year }_{t}=t\right]\right)+\gamma_{c}+\rho_{t}+\epsilon_{i c t}
$$

where pollution $P_{i c t}$ for person $i$ residing in $\mathrm{CZ} c$ in year $t$ is regressed on a series of interaction terms for whether a CZ is newly designated as nonattainment for the PM2.5 standard $\left(1\left[\right.\right.$ Nonattain $\left.\left._{c}\right]=1\right)$ interacted with a dummy for each year before and after the regulations went into place. Equation (2) also controls for county fixed effects $\gamma_{c}$ and (state-)year fixed effects $\rho_{t}$. All regressions are weighted using Census survey weights, and standard errors are clustered at the CZ level.

The coefficients of interest, $\beta_{t}$, compare the CZs that became newly regulated under the PM2.5 standard to areas that were in compliance with the standard, before and after the regulations went into place. The identifying assumption is that the newly regulated CZs would have trended similarly, in terms of pollution levels, to the unregulated CZs in the absence of the treatment. Alternatively, the identifying assumption relies on there being no common shock to the treated CZs in the years after the regulations went into place. ${ }^{14}$

\footnotetext{
${ }^{13}$ There is no formal EPA definition of "air regions", as they are decided on a case-by-case basis. Thus, air regions are only defined for nonattainment areas. Our use of commuting zone boundaries is meant to approximate air region boundaries in the attainment areas. In practice, our results are not sensitive to using either county or commuting zone boundaries to assign treatment/control, but we chose the latter to better mimic the regulatory variation while also accounting for potential spatial correlation in treatment.

${ }^{14}$ Once potential concern may be state-level regulations which coincide with the PM2.5 standards, however, these changes
} 
While these assumptions are inherently untestable, the event study design affords us a useful indirect test; we can examine the event study coefficients and trends leading up to the regulation in pollution levels between the regulated and unregulated CZs and test whether the two groups were trending similarly in the years prior to the regulation going into place.

We also estimate a version of equation (2) with an additional, three-way interaction term between indicators for ever being in nonattainment status, year, and whether the individual is African American. ${ }^{15}$ This "triple-difference" regression equation allows the impact of the CAA to vary differentially by race (i.e. do black neighborhoods clean up more or less in newly regulated CZs when compared to white neighborhoods)?

Lastly, we explore how the CAA regulatory variation affects different quantiles of the pollution distribution. The basic idea is to combine our difference-in-difference estimator with quantile regression methods to estimate the counterfactual outcome distribution in the absence of the policy intervention. We can then compare this no-regulation, counterfactual distribution to the actual outcome distribution when subject to the policy intervention. We can go further to calculate mean black-white gaps in pollution exposure in this counterfactual world, to better understand the role of the CAA in contributing to the convergence of black-white pollution levels.

Recent advances in quantile regression allow us to estimate the causal effect of the Clean Air Act's PM2.5 National Ambient Air Quality Standard on the unconditional pollution distribution (Firpo et al. 2009). The basic idea is to transform the problem by considering a covariate's influence on population shares rather than quantiles. By estimating how a covariate (e.g., nonattainment status) affects the share of the population below various pollution thresholds, the semi-elasticities show the effect of an increase in CAA regulatory stringency on the cumulative distribution function (CDF) of pollution (see e.g., Chernozhukov et al. 2013). We can then invert the impact of nonattainment on the CDF of pollution to estimate the impact on a pollution quantile. The re-centered influence function (RIF) regression approach proposed by Firpo et al. (2009) performs this inversion using a local linear approximation to the counterfactual CDF, rescaling the marginal effect of the CAA on the population share above a pollution cutoff by the probability density of pollution at that cutoff.

should be absorbed in the state-year fixed effects.

${ }^{15}$ Formally, we estimate the following equation

$$
P_{\text {let }}=\sum_{t=2000}^{2015} \beta_{t}\left(1\left[\text { Nonattain }_{c}\right] \times 1\left[\text { year }_{t}=t\right] \times 1[\text { African American } i]\right)+\Gamma_{i c t}+\gamma_{c}+\rho_{t}+X^{\prime} \eta+\epsilon_{i c t}
$$

where the vector $\Gamma_{i c t}$ includes the full set of two-way interaction terms to facilitate interpretation. 
In practice, RIF regression requires first transforming the outcome variable, PM2.5 pollution, using a recentered influence function before projecting this transformation onto the explanatory variables of interest. Firpo et al. (2009) consider the following model of pollution $P$ :

$$
P=h(X, \epsilon)
$$

where $X$ represents the set of independent, explanatory variables and $\epsilon$ is the scalar unobserved error term. The unconditional partial effect is defined as the shift in the distribution of a variable $X$ on the distributional statistic $v\left(F_{P}\right)$, which can be expressed as:

$$
\int \frac{d E[\operatorname{RIF}(P, v) \mid X=x]}{d x} d F(x),
$$

where $\operatorname{RIF}(P, v)$ is the recentered influence function. When the distributional statistic $v$ is the $\tau$ th quantile function $q_{t}=\inf _{q}\left\{q: F_{P}(q) \geq \tau\right\}$ the $\operatorname{RIF}\left(P, q_{\tau}\right)$ can be represented as

$$
\operatorname{RIF}\left(P, q_{\tau}\right)=q_{\tau}+\frac{\tau-1\left\{p \leq q_{\tau}\right\}}{f_{P}\left(q_{\tau}\right)},
$$

where $f_{P}\left(q_{\tau}\right)$ is the density function of pollution $P$ evaluated at quantile $q_{\tau}$.

The relevant property of a re-centered influence function is that its expectation equals the distributional statistic of interest. For quantile $\tau$ denoted $Q_{\tau}$, the quantile $\operatorname{RIF}$ is given by $\operatorname{RIF}\left(p, Q_{\tau}\right)=Q_{\tau}+\frac{\tau-\mathbf{1}\left(p<Q_{\tau}\right)}{f_{p}\left(Q_{\tau}\right)}$ and taking expectations verifies $E\left[R I F\left(p, Q_{\tau}\right)\right]=Q_{\tau}$. Since the mean of the RIF is equal to the quantile, we can use the law of iterated expectations to go between conditional and unconditional partial effects. Firpo et al. (2009) show that a regression of the RIF on covariates yields the approximate effect of the covariates on the distributional statistic of interest (applied to the unconditional distribution). This feature of RIF regressions allows researchers to estimate how treatment effects (e.g., the effects of the CAA PM2.5 regulations on county-year pollution levels) map into the unconditional distribution of pollution.

In practice, this exercise entails first defining a series of pollution cutoffs corresponding to specified quantiles of the empirical pollution distribution, and then for each cutoff, estimating the effect of the Clean Air Act's PM2.5 NAAQS policy on the probability of being above that cutoff. We begin by creating 19 RIF statistics, one for each pollution vigintile from the 5 th to the 95 th percentiles of the pollution distribution. We then replace the dependent variable in equation (2) with one of the RIF-quantile statistics. The event study 
coefficients for each RIF-quantile can be interpreted as the effect of the PM2.5 nonattainment designations on the qth quantile of the unconditional PM2.5 exposure distribution.

Figure 8 presents the estimated event-study coefficients $\hat{\beta}_{t}$ from a version of equation (2) where the dependent variable is the pollution level for an individual survey respondent in a given year. There are two main findings. First, in the years leading up to the implementation of the regulation, the trends in air quality between the newly regulated counties and the unregulated counties are not statistically different from zero. After 2005, when the policy was first enacted, pollution levels in newly regulated counties fall by about $8 \%$ and remain there through the end of our sample.

Table 3 presents the difference-in-difference analog to Figure 8 and equation (2). In particular, we replace the $1[$ year $=t]$ variable in equation $(2)$ with a single indicator equal to one for year $>=2005$ :

$$
P_{i c t}=\beta\left(1\left[\text { Nonattain }_{c}\right] \times 1\left[\text { year }_{t} \geq 2005\right]\right)+\gamma_{c}+\rho_{t}+X^{\prime} \eta+\epsilon_{i c t}
$$

The regression coefficient of interest $\beta$ from this more parsimonious model tells us the average difference in pollution levels in the years after, relative to before, comparing regulated counties to counties not subject to the regulation. Column (1) suggests that PM2.5 levels fell by $1.23 \mu \mathrm{g} / \mathrm{m}^{3}$ in nonattainment counties in the years after the regulation went into place. Column (3) presents the same model except the dependent variable has been transformed via the natural log. As suggested by the figures, these estimates suggest that pollution levels in newly regulated counties improved by about 8 percent in the years after the policy went into place.

The even columns of Table 3 add a triple interaction between the county ever being in non-attainment status, a post-2005 time period, and an indicator for whether the individual is African American. Recall that African Americans and non-Hispanic whites tend to live in different parts of the same counties, so there is scope for regulation at the county-level to have a differential impact on different communities within a county. These estimates suggest that the within-county improvements in air quality were slightly less for African Americans than for non-Hispanic whites, though the difference is not statistically significant in the $\log$ specification.

Columns (5) through (8) of Table 3 add state-by-year fixed effects to equation (3) to control for any unobserved, statewide changes to air quality that are common to all individuals in a given state-year. These controls substantially attenuate the coefficients from columns (1) through (4) by almost 50 percent. There 
are potentially many reasons for this attenuation, having to do with unobserved, time-varying correlated unobservables. From this point forward, we treat the estimates with state-by-year fixed effects as our preferred specification in order to flexibly control for this potential form of omitted variable bias.

While the estimates from Figure 8 and Table 3 tell us about the average effects in the treated counties, relative to the controls, they tell us little about other parts of the pollution distribution that might otherwise be affected by this increased regulatory stringency. To explore the distributional impacts of the PM2.5 NAAQS we next turn to our unconditional quantile regression estimates. Figure 9 presents nineteen separate regression estimates of $\beta$ from equation (3), where we replace the dependent variable in this model with the RIF counterpart for each respective pollution quantile. The figure visually summarizes the effect of the PM2.5 nonattainment designation on different quantiles of the unconditional PM2.5 pollution distribution. The estimates suggest that the most significant effects of the new standards were to improve air quality in areas between the 50th and 90th percentiles of PM2.5 distribution. This result must be true almost by construction, as the PM2.5 standards only bind at the upper quantiles of the pollution distribution. It is somewhat surprising to see that the estimated effect of the regulations are somewhat smaller at the 95th percentile of the pollution distribution than at the 50th-80th percentiles. This smaller effect may be partly due to the fact that the EPA and local regulators have faced severe difficulties in addressing air quality problems in the most severely polluted parts of the country (e.g., the San Joaquin Valley or parts of Southern California).

Figure 10 presents RIF-Quantile regression results that estimate each quantile specific RIF separately by race. This results in 38 versions of equation (3), and the corresponding estimates are plotted in Figure 10. While the estimates from Table 3 suggested there was little difference in the treatment effects of nonattainment between African Americans and non-Hispanic whites on average (see e.g., Column (6)), the results in Figure 10 suggest that at the upper quantiles of the pollution distribution, African Americans have seen larger improvements in air quality relative to their non-Hispanic white counterparts. For visual clarity, we have omitted the associated confidence intervals, but they are shown in Appendix Figure B2. In general, the race-specific confidence intervals overlap with one another, and thus it is difficult to reject the null that the treatment effects at each quantile are equal. 


\subsection{What Fraction of Black-White Convergence is Attributable to the CAA Regulation of PM2.5?}

We can use the RIF estimates from Figure 10, combined with population shares of African Americans and non-Hispanic whites in each vigintile of the initial distribution of PM2.5, to compute counterfactual pollution levels in the absence of the implementation of the nonattainment designations. ${ }^{16}$ Table 4 walks through these calculations. Columns (1) and (2) of the top panel describe actual pollution levels within each quantile bin in 2005 and 2015, respectively. Columns (3) and (4) use estimates from Figure 10 to calculate what pollution in each quantile would have been in 2015 in the absence of the CAA PM2.5 NAAQS implementation, separately for African Americans and non-Hispanic whites.

The second panel of Table 4 considers the counterfactual gap that would have existed in 2015 in the absence of the CAA PM2.5 NAAQS. The actual gap in 2015 was $0.61 \mu \mathrm{g} / \mathrm{m}^{3}$, whereas the counterfactual gap is $0.97 \mu \mathrm{g} / \mathrm{m}^{3}$. The actual change in the black-white gap between 2005 and 2015 was $0.59 \mu \mathrm{g} / \mathrm{m}^{3}$, and the implied counterfactual change is a narrowing of $0.23 \mu \mathrm{g} / \mathrm{m}^{3}$. Since, we would have observed a $0.23 \mu \mathrm{g} / \mathrm{m}^{3}$ improvement in the black-white gap in the absence of the policy, we conclude that the CAA can account for over $60 \%$ of the relative improvement in black-white outcomes. ${ }^{17}$

The last panel of Table 4 considers an alternative counterfactual, recognizing that there may have been some endogenous mobility in response to these CAA-induced improvements in air quality that may have attenuated or exacerbated the relative improvements in outcomes between African Americans and nonHispanic whites. To explore this counterfactual, we weight columns (3) and (4) by the pre-regulation, 2005 population shares of whites and blacks in the respective quantile bins. Holding fixed the relative population shares, the no-regulation, counterfactual change in the black-white pollution exposure gap would have been only $0.04 \mu \mathrm{g} / \mathrm{m}^{3}$ instead of $0.59 \mu \mathrm{g} / \mathrm{m}^{3}$. Thus, between 2005 and 2015 there were large relative shifts in population that unraveled some of the relative black-white convergence in mean air quality exposure.

Appendix Figure B3 explores this mobility response in more detail. Figure B3a plots the change in the black population share between 2005 and 2015, separately by pollution quantile; negative numbers imply a reduction in the black share in the particular quantile bin over this time period. These changes in population are plotted against the RIF-quantile treatment effects for blacks in the respective quantile (i.e.

\footnotetext{
${ }^{16}$ For the calculations in this exercise, we use tract-level population shares by race from the public-use American Community Survey 5-year files.

${ }^{17}$ This is calculated as $(0.59-0.23) / 0.59$.
} 
taken from Figure 10). We include a linear fit that suggests the areas that saw the largest improvements for African Americans over this time period are also the areas where the share of African Americans declined the most. Figure B3b shows the opposite is true for non-Hispanic whites. The quantiles which saw the largest improvements in air quality for non-Hispanic whites saw the largest increases in white population shares over this time period. These relative shifts in mobility served to offset some of the CAA-induced convergence over this time period.

How does one reconcile the results in Figure B3 with the earlier mobility results from Table 2 that suggested whites have moved to relatively more polluted areas in 2015 versus where they were in 2000? These findings are not necessarily inconsistent with one another. While whites are disproportionately moving to urban areas (i.e. Table 2), they are moving to the urban areas that have experienced large improvements in air quality between 2000-2015 (i.e. Figure B3). By the same token, African-Americans who were already living in polluted urban areas became less dominant in these areas by 2015 as non-Hispanic whites moved in and so saw less of the gains than they otherwise would have.

\section{Conclusion}

This paper shows that racial differences in ambient particulate exposure declined significantly between 2000 and 2015. We add to the small but growing literature using high-resolution, nationwide data on pollution to examine racial differences in potential pollution exposure. We focus on PM2.5 and show that the gap between African Americans and non-Hispanic whites narrowed from $-1.6 \mu \mathrm{g} / \mathrm{m}^{3}$ in 2000 to $-0.5 \mu \mathrm{g} / \mathrm{m}^{3}$ by 2015. To our knowledge, this is the first paper to explore the underlying causal drivers that contributed to the narrowing of this gap. We find that very little of the decline in the gap in mean exposure levels can be accounted for by changes in mobility, individual, or household-level characteristics. Similarly, we find that racial gaps in exposure have narrowed at each quantile of the PM2.5 distribution, and that little of this narrowing can be explained by the demographic characteristics available in Census Bureau data. Instead, we find that virtually all of the closure of the gap is due to falling pollution levels in the areas where African Americans are more likely to live. There is little evidence that movement of African Americans to relatively cleaner neighborhoods or non-Hispanic whites to relatively dirtier neighborhoods has played a significant role in the observed convergence.

Why then has pollution fallen faster in areas that are home to disproportionate numbers of African 
Americans? Since African Americans have historically been concentrated in areas with more polluted air, and because the CAA targets the dirtiest areas for cleanup, it is reasonable to expect that the CAA could have a disproportionate impact on African Americans. However, set against this expectation are market forces that might cause African Americans in search of lower rents to move away from newly cleaner places. Our analysis shows that implementation of new PM2.5 standards in 2005 sharply reduced pollution in a way that was sustained over time and is responsible for much of the closure of the racial gap in PM2.5 exposure between 2000 and 2015. We find some evidence, however, to suggest that changes in PM2.5 levels were associated with re-sorting of African Americans across areas in ways that undid some of these gains.

These findings suggest that the CAA has likely played a significant role in reducing the black-white gaps in exposure to air pollution, because the legislation systematically targeted the dirtiest areas for cleanup, and African Americans were disproportionately likely to live in areas with dirty air. Hence, although the CAA was not explicitly designed to address disparities in pollution exposure, the CAA has nonetheless contributed to reductions in environmental inequality between racial groups in the United States.

\section{References}

Abel, T. D., And J. White (2011): "Skewed riskscapes and gentrified inequities: environmental exposure disparities in Seattle, Washington," American journal of public health, 101(S1), S246-S254.

ARD, K. (2015): "Trends in exposure to industrial air toxins for different racial and socioeconomic groups: A spatial and temporal examination of environmental inequality in the US from 1995 to 2004," Social Science Research, 53, 375-390.

Banzhaf, S., L. Ma, and C. Timmins (2019): "Environmental justice: The economics of race, place, and pollution," Journal of Economic Perspectives, 33(1), 185-208.

Baum-Snow, N., and D. Hartley (2019): “Accounting for central neighborhood change," Working Paper.

Blinder, A. S. (1973): "Wage discrimination: reduced form and structural estimates," Journal of Human resources, pp. 436-455.

Brajer, V., And J. V. Hall (2005): "Changes in the distribution of air pollution exposure in the Los Angeles basin from 1990 to 1999," Contemporary Economic Policy, 23(1), 50-58.

Chavis, B. F., And C. Lee (1987): "Toxic wastes and race in the United States: A national report on the racial and socio-economic characteristics of communities with hazardous waste sites," New York: Commission for Racial Justice, United Church of Christ.

Chay, K. Y., And M. Greenstone (2003): "Air quality, infant mortality, and the Clean Air Act of 1970," Discussion paper, National Bureau of Economic Research. 
Clark, L. P., D. B. Millet, and J. D. Marshall (2014): "National patterns in environmental injustice and inequality: outdoor NO2 air pollution in the United States," PloS one, 9(4), e94431.

(2017): "Changes in transportation-related air pollution exposures by race-ethnicity and socioeconomic status: outdoor nitrogen dioxide in the United States in 2000 and 2010," Environmental health perspectives, 125(9), 097012.

Couture, V., And J. Handbury (2017): "Urban revival in America, 2000 to 2010," Discussion paper, National Bureau of Economic Research.

Currie, J., And R. Walker (2019): "What Do Economists Have to Say about the Clean Air Act 50 Years after the Establishment of the Environmental Protection Agency?," The Journal of Economic Perspectives, $33(4), 3-26$.

Depro, B., C. Timmins, and M. O'Neil (2015): "White flight and coming to the nuisance: can residential mobility explain environmental injustice?," Journal of the Association of Environmental and resource Economists, 2(3), 439-468.

Di, Q., I. Kloog, P. Koutrakis, A. Lyapustin, Y. Wang, and J. Schwartz (2016): "Assessing PM2. 5 exposures with high spatiotemporal resolution across the continental United States," Environmental science \& technology, 50(9), 4712-4721.

Dinardo, J., N. M. Fortin, and T. Lemieux (1996): "Labor Market Institutions and the Distribution of Wages, 1973-1992: A Semiparametric Approach," Econometrica, 64(5), 1001-1044.

Firpo, S., N. M. Fortin, And T. Lemieux (2009): "Unconditional quantile regressions," Econometrica, $77(3), 953-973$.

Fowlie, M., E. Rubin, and R. Walker (2019): "Bringing Satellite-Based Air Quality Estimates Down to Earth," in AEA Papers and Proceedings, vol. 109, pp. 283-88.

Hipp, J. R., AND C. M. LAKOn (2010): "Social disparities in health: disproportionate toxicity proximity in minority communities over a decade," Health \& place, 16(4), 674-683.

Hsiang, S., P. Oliva, and R. Walker (2019): "The distribution of environmental damages," Review of Environmental Economics and Policy, 13(1), 83-103.

Isen, A., M. Rossin-Slater, And W. R. Walker (2017): "Every breath you take - every dollar you'll make: The long-term consequences of the clean air act of 1970," Journal of Political Economy, 125(3), 848-902.

Kravitz-Wirtz, N., K. Crowder, A. Hajat, and V. Sass (2016): "The long-term dynamics of racial/ethnic inequality in neighborhood air pollution exposure, 1990-2009," Du Bois review: social science research on race, 13(2), 237-259.

Liebler, C. A., S. R. Porter, L. E. Fernandez, J. M. Noon, and S. R. Ennis (2017): "America's churning races: Race and ethnicity response changes between Census 2000 and the 2010 Census," Demography, 54(1), 259-284.

Logan, T. D., and J. M. Parman (2017): "The National Rise in Residential Segregation," The Journal of Economic History, 77(1), 127-170.

Mohai, P., D. Pellow, and J. T. Roberts (2009): "Environmental justice," Annual review of environment and resources, 34, 405-430. 
Mohai, P., and R. Saha (2006): "Reassessing racial and socioeconomic disparities in environmental justice research," Demography, 43(2), 383-399.

OAXACA, R. (1973): "Male-female wage differentials in urban labor markets," International economic review, pp. 693-709.

Office, U. G. A. (1983): "Siting of hazardous waste landfills and their correlation with racial and economic status of surrounding communities," GAOfRCED-83-168. Washington, DC: US. General Accounting Office.

Pais, J., K. Crowder, and L. Downey (2013): "Unequal trajectories: Racial and class differences in residential exposure to industrial hazard," Social Forces, 92(3), 1189-1215.

Van Donkelaar, A., R. V. Martin, M. Brauer, N. C. Hsu, R. A. Kahn, R. C. Levy, A. Lyapustin, A. M. SAYER, AND D. M. Winker (2016): "Global estimates of fine particulate matter using a combined geophysical-statistical method with information from satellites, models, and monitors," Environmental science \& technology, 50(7), 3762-3772.

Voorheis, J., ET AL. (2017): "Longitudinal Environmental Inequality and Environmental Gentrification: Who Gains From Cleaner Air?," Discussion paper, Center for Economic Studies, US Census Bureau. 


\section{Tables and Figures}

Figure 1: Trends in Pollution Exposure by Race

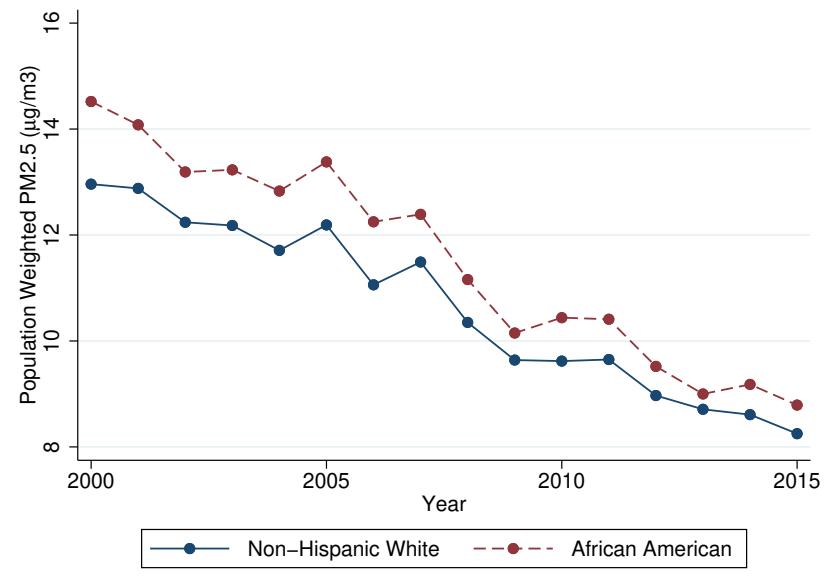

Notes: This figure plots mean PM2.5 exposure by year, separately for African-Americans and the non-Hispanic white population. Source: 2000 Decennial Census, American Community Survey 2001-2015, and Di et al. (2016).

Figure 2: Distributions of Pollution Exposure, 2000 and 2015
(a) 2000
(b) 2015
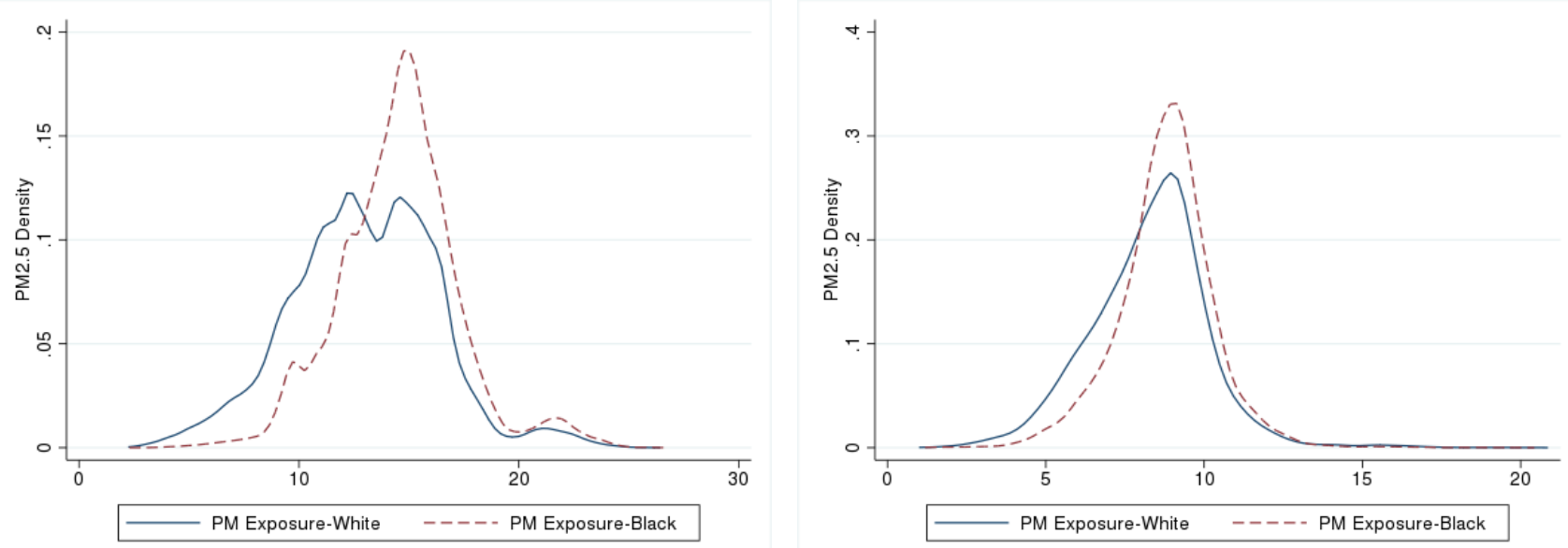

Notes: This figure plots the PM2.5 density, separately for African-Americans and the non-Hispanic white population in both 2000 and 2015. Due to Census Bureau disclosure avoidance review guidelines, we trim the upper 97th and lower 3rd percentiles of each density. Source: 2000 Decennial Census, American Community Survey 2001-2015, and Di et al. (2016). 
Figure 3: Residual Black-White Pollution Gap: PM2.5

(a) Conditional Gap with 95\% Confidence Intervals

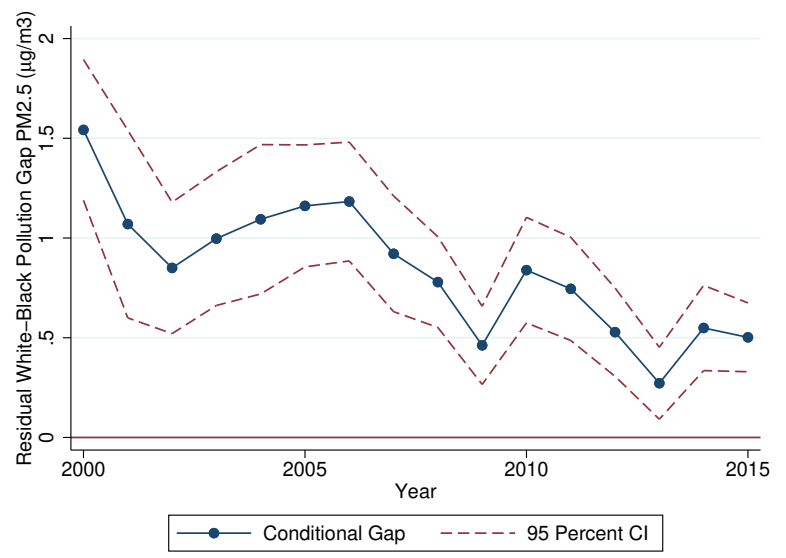

(b) Conditional vs. Unconditional Gap

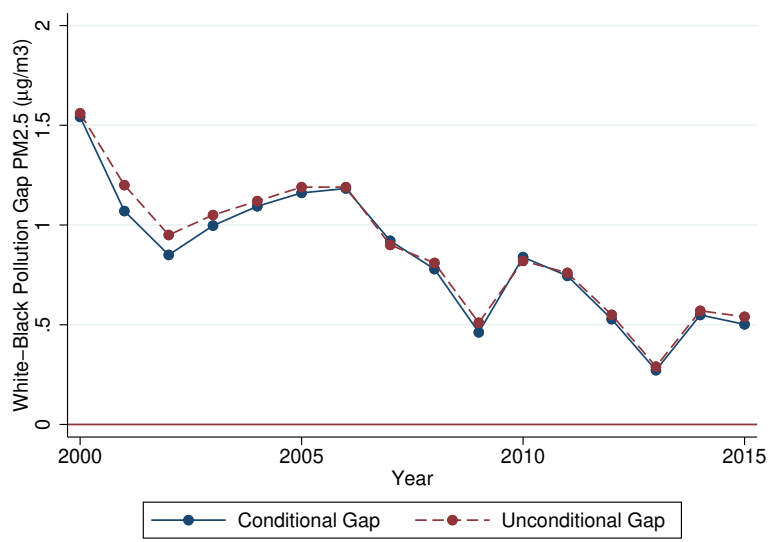

Notes: Figure (a) plots the regression coefficients from 15 separate estimates of equation (1), regressing pollution on an indicator for whether an individual is an African-American, controlling for individual and household characteristics. The coefficient estimates correspond to the conditional mean black-white difference in air pollution, after adjusting for differences in observable individual and household characteristics. Dashed lines correspond to 95 percent confidence intervals, where standard errors have been clustered by commuting zone. Regressions are weighted using Census survey weights. Figure (b) compares the conditional mean coefficients to the unconditional mean differences by year. See text for details. Source: 2000 Decennial Census, American Community Survey 2001-2015, and Di et al. (2016).

Figure 4: Actual versus Counterfactual African American Pollution Distribution: PM2.5

(a) Reweighted vs. Actual PM2.5 Density

African Americans, 2000

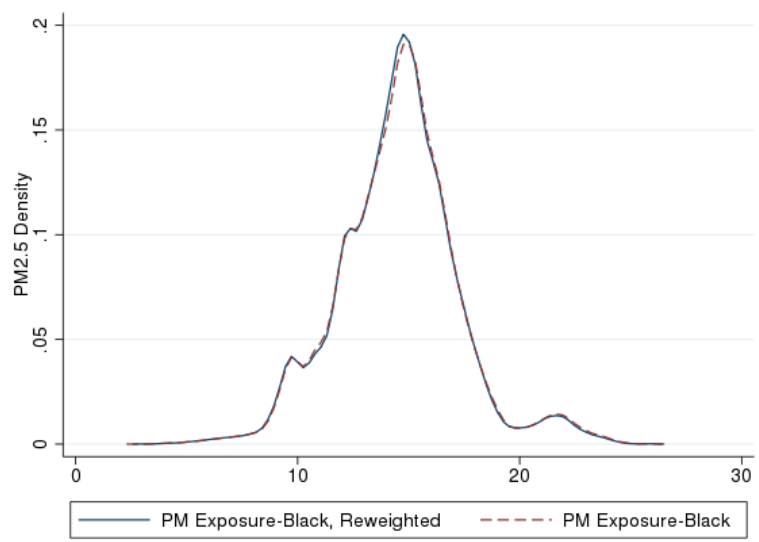

(b) Reweighted vs. Actual PM2.5 Density

African Americans, 2015

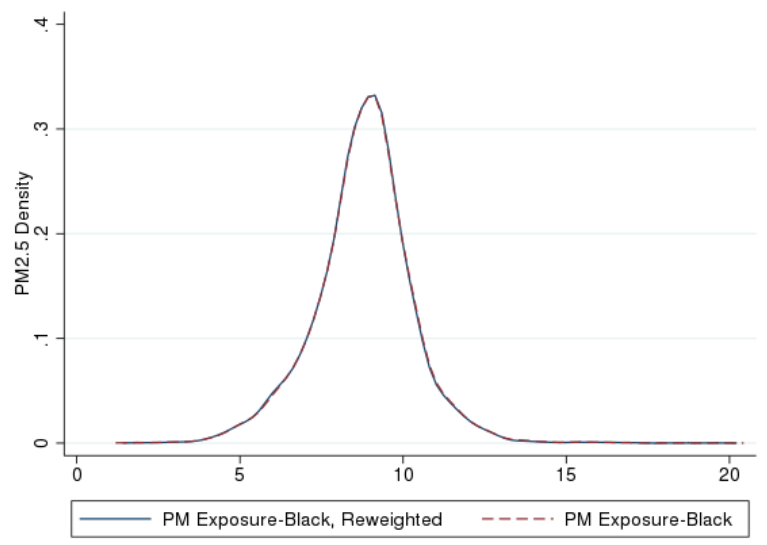

Notes: These figures plot the actual versus counterfactual densities of pollution exposure for African Americans in 2000 and 2015. The counterfactual densities stem from an application of Dinardo, Fortin, Lemieux (1996), whereby we reweight the African American pollution distribution to reflect what the distribution would have looked like if they had the same individual characteristics as non-Hispanic whites in our sample. See text for details. Source: 2000 Decennial Census, American Community Survey 2001-2015, and Di et al. (2016). 
Figure 5: Residual Black-White Pollution Gap After Controlling for Neighborhood Characteristics: PM2.5

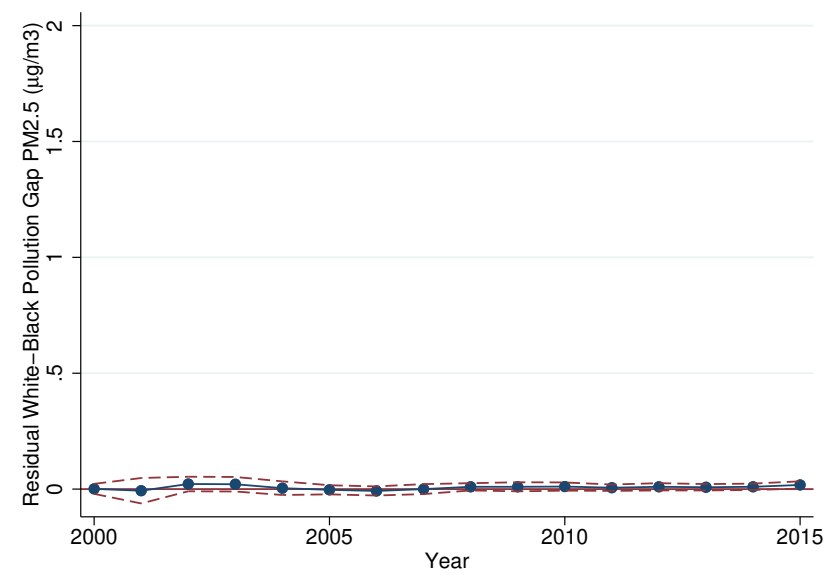

Notes: This figure plots the regression coefficients from 15 separate estimates of equation (1), regressing pollution on an indicator for whether an individual is an African-American, controlling for individual, household, and Census tract characteristics. The coefficient estimates correspond to the conditional mean black-white difference in air pollution, after adjusting for differences in observable individual, household, and Census tract characteristics. Dashed lines correspond to 95 percent confidence intervals, where standard errors have been clustered by commuting zone. Regressions are weighted using Census survey weights. See text for details. Source: 2000 Decennial Census, American Community Survey 2001-2015, and Di et al. (2016). 
Figure 6: Racial Distribution of Population and Impact of CAA by Pollution Decile

(a) Distribution of African-American and non-Hispanic White population by decile of PM2.5 in 2000

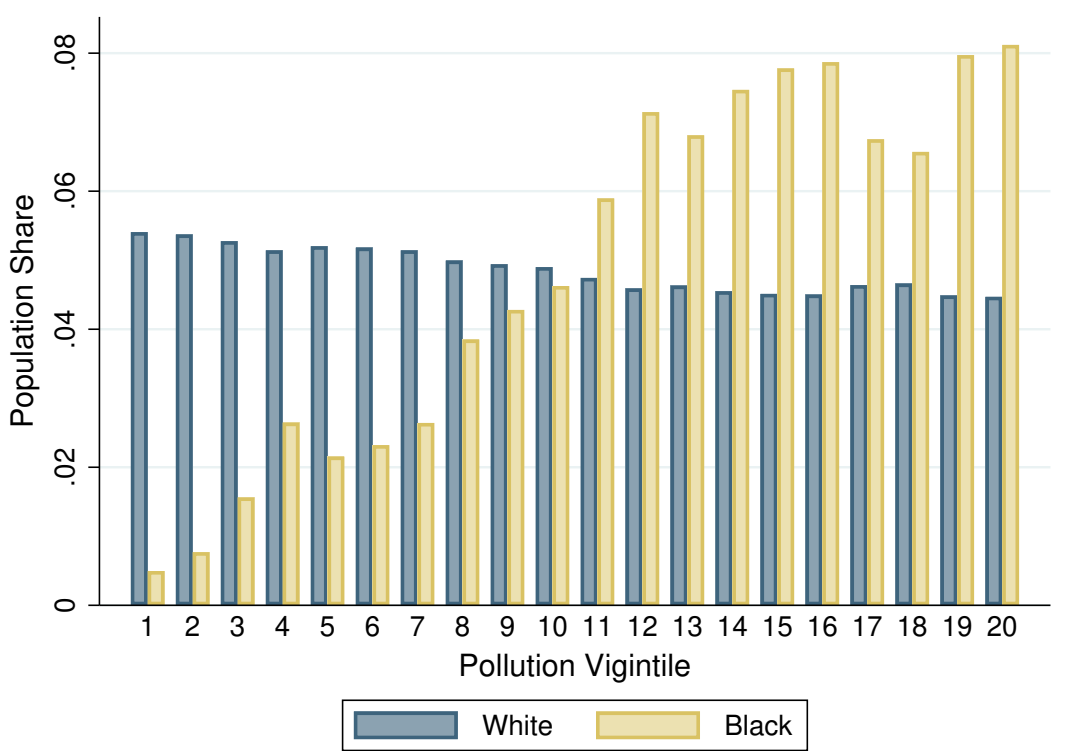

(b) Counties impacted by the CAA, by decile of PM2.5 in 2005

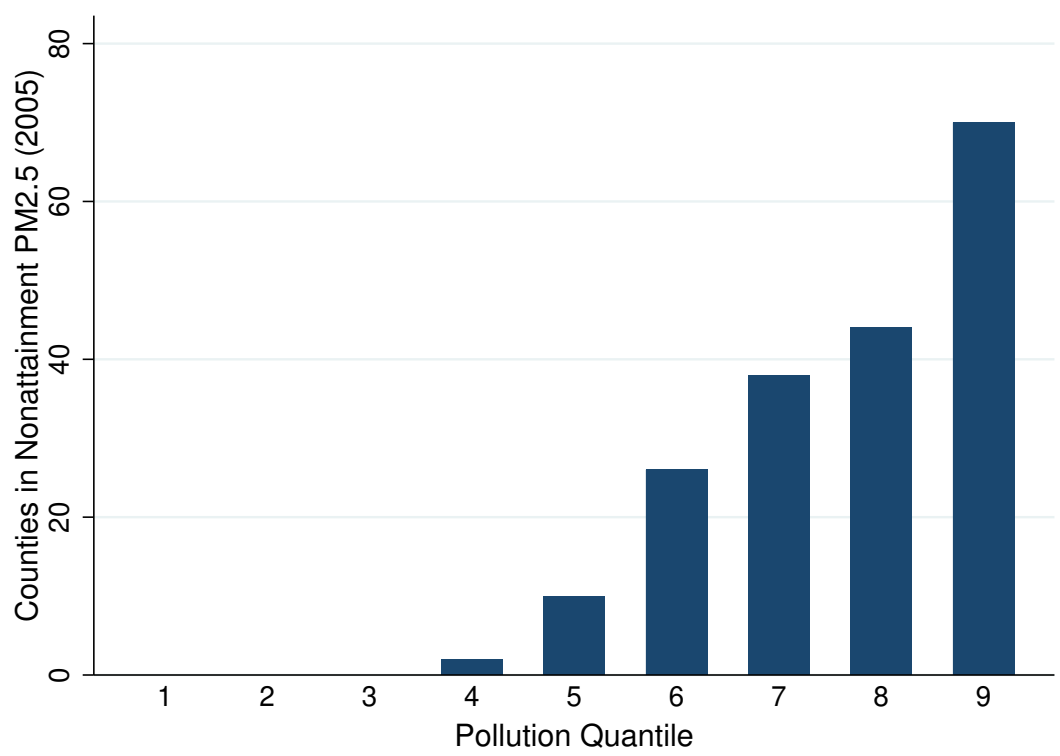

Notes: Figure 6a plots population shares by pollution decile, separately for African American and non-Hispanic whites. Figure 6b shows the total number of counties subject to the Clean Air Act's 1997 NAAQS PM2.5 standard, by pollution decile. Source: 2000 Decennial Census, American Community Survey 2001-2015, EPA NAAQS Greenbook, and Di et al. (2016). 
Figure 7: Commuting Zones in Nonattainment After the Adoption of the PM2.5 National Ambient Air Quality Standards

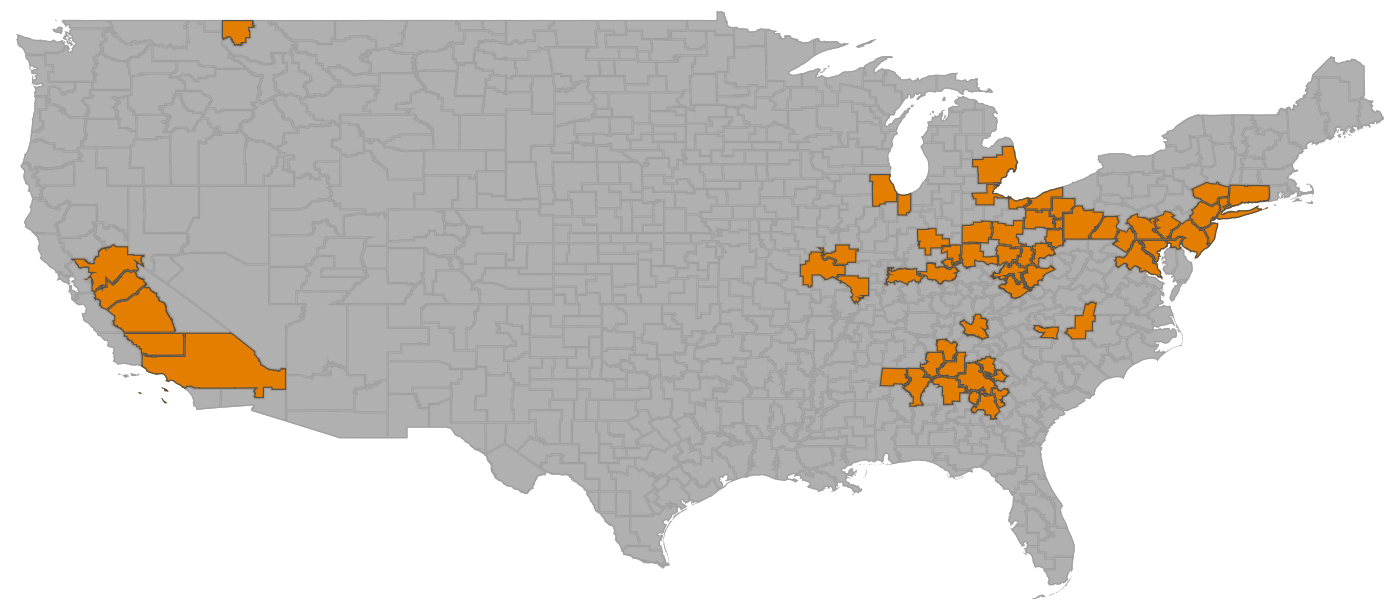

Notes: This figure plots all the commuting zones containing at least one nonattainment county in 2005 for the Clean Air Act's 1997 NAAQS PM2.5 standard. While the PM2.5 NAAQS was initially proposed in 1997, the first year of regulatory enforcement began in 2005. Source: EPA NAAQS Greenbook.

Figure 8: The Effect of the PM2.5 NAAQS on Newly Regulated Commuting Zones

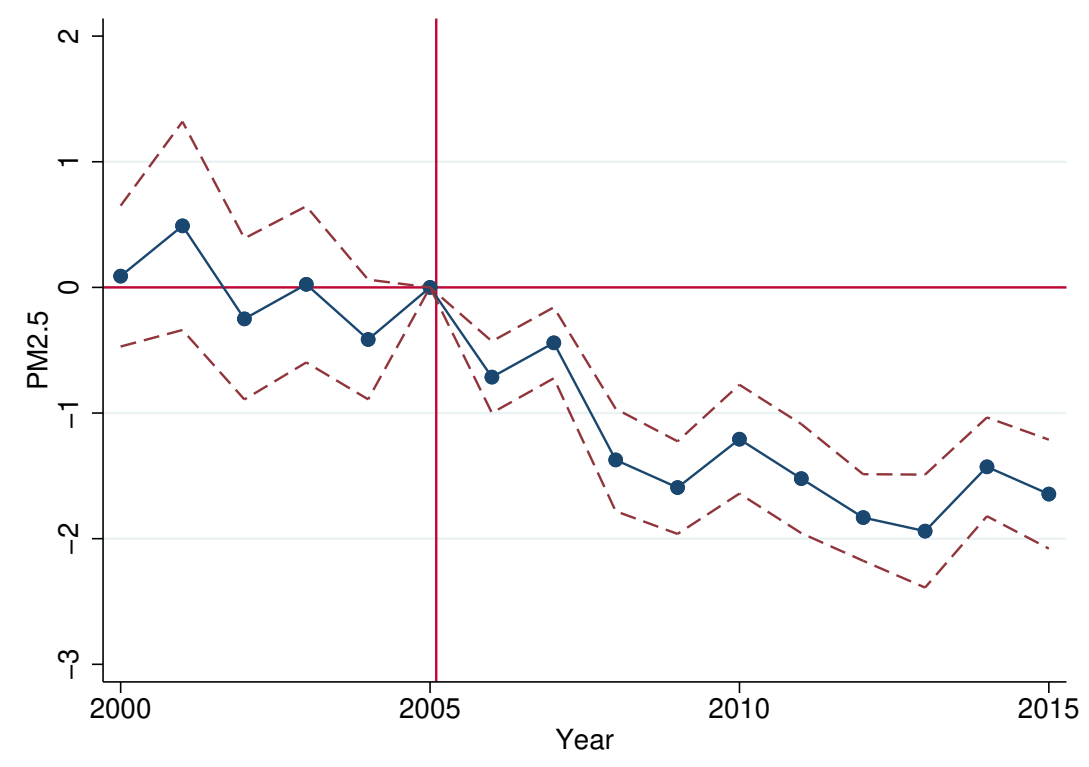

Notes: This figure plots the event-time coefficient estimates from a version of equation (2), where the dependent variable consists of PM2.5 exposure $\left(\mu \mathrm{g} / \mathrm{m}^{3}\right)$ for a given individual-year. The regression model controls for county and year fixed effects. The dashed lines represent $95 \%$ confidence intervals. Regressions are weighted by Census survey weights and errors are clustered by commuting zone. Source: 2000 Decennial Census, American Community Survey 2001-2015, EPA NAAQS Greenbook, Di et al. (2016). 
Figure 9: RIF-Quantile Treatment Effects of the 2005 CAA PM2.5 NAAQS Implementation

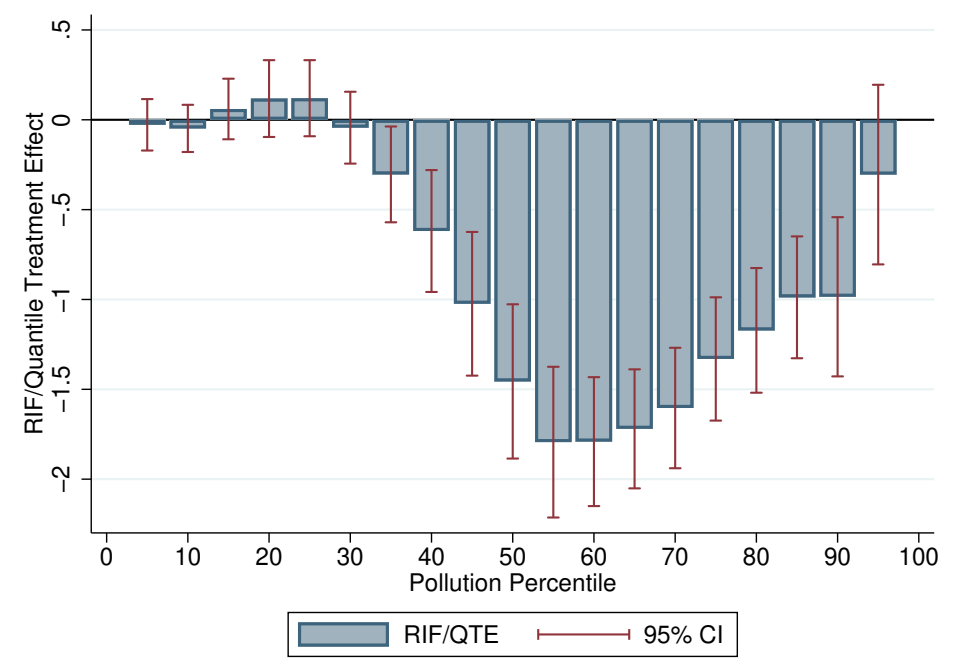

Notes: This figure plots the regression coefficient $\hat{\beta}$ from 19 separate versions of equation (3), where the dependent variable consists of the RIF-Quantile transformation of the respective PM2.5 vigintile (indicated by the x-axis). The regression model controls for county fixed effects and state-by-year fixed effects. The solid red lines represent $95 \%$ confidence intervals. Regressions are weighted by Census survey weights and errors are clustered by commuting zone. Source: 2000 Decennial Census, American Community Survey 2001-2015, EPA NAAQS Greenbook, Di et al. (2016).

Figure 10: Race-Specific RIF-Quantile Treatment Effects of the 2005 CAA PM2.5 NAAQS Implementation

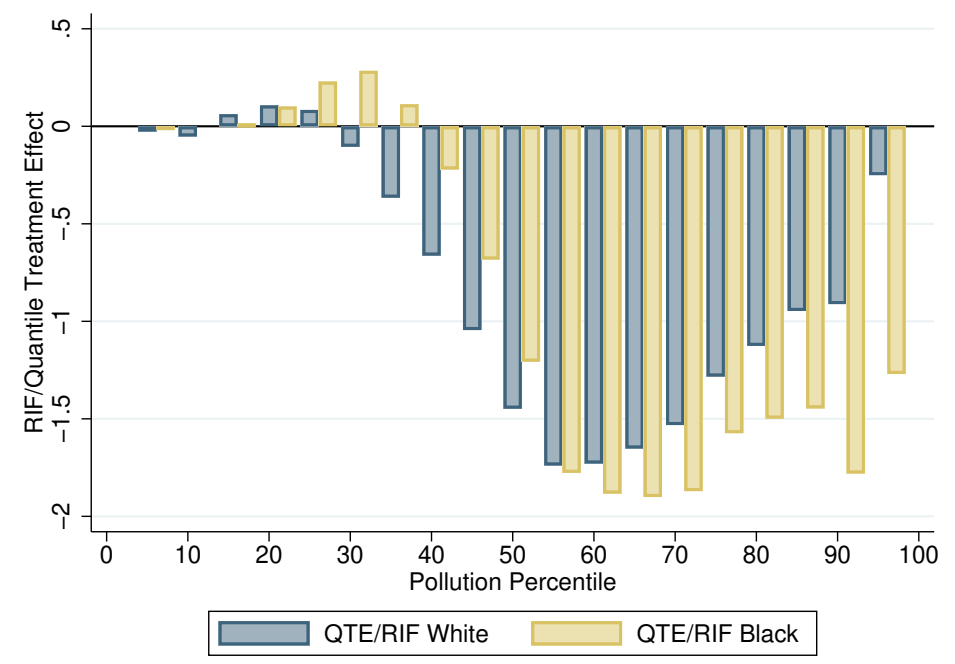

Notes: This figure plots the regression coefficient $\hat{\beta}$ from 38 separate versions of equation (3), 19 regressions for each race, where the dependent variable consists of the RIF-Quantile transformation of the respective PM2.5 vigintile (indicated by the x-axis). The regression model controls for county fixed effects and state-by-year fixed effects. Regressions are weighted by Census survey weights and errors are clustered by commuting zone. Source: 2000 Decennial Census, American Community Survey 2001-2015, EPA NAAQS Greenbook, Di et al. (2016). 
Table 1: Residual Black-White Pollution Gap by Income Quintile: PM2.5

\begin{tabular}{lccccc}
\hline & \multicolumn{5}{c}{ Income Quintile } \\
& 1 & 2 & 3 & 4 & 5 \\
\cline { 2 - 6 } & \multicolumn{5}{c}{ Panel A: Year 2000 } \\
1[African-American] & 1.535 & 1.603 & 1.616 & 1.590 & 1.396 \\
Observations & $(0.180)$ & $(0.190)$ & $(0.193)$ & $(0.195)$ & $(0.183)$ \\
& 1791000 & 1967000 & 2397000 & 2277000 & 2204000 \\
\cline { 2 - 6 } & \multicolumn{5}{c}{ Panel B: Year 2015 } \\
\cline { 2 - 6 } 1[African-American] & 0.499 & 0.463 & 0.512 & 0.558 & 0.570 \\
Observations & $(0.097)$ & $(0.093)$ & $(0.096)$ & $(0.089)$ & $(0.099)$ \\
& 235000 & 223000 & 224000 & 226000 & 244000 \\
\hline
\end{tabular}

Notes: This table presents the regression coefficients from 10 separate estimates of equation (1), 5 per panel. We regress pollution on an indicator for whether an individual is an African-American, controlling for individual and household characteristics, and we stratify the data by income quintile. The coefficient estimates correspond to the conditional mean black-white difference in air pollution, after adjusting for differences in observable individual and household characteristics. Panel A does this for the year 2000, and Panel B repeats this exercise in 2015. Regressions are weighted using Census survey weights, and standard errors are clustered by commuting zone. See text for details. Source: 2000 Decennial Census, American Community Survey 2001-2015, and Di et al. (2016).

Table 2: Counterfactual Pollution Levels and Gaps Holding Location Fixed

\begin{tabular}{lcc|c}
\hline & $\begin{array}{c}(1) \\
\text { Actual 2000 } \\
\text { Exposure }\end{array}$ & $\begin{array}{c}(2) \\
\text { Actual 2015 } \\
\text { Exposure }\end{array}$ & $\begin{array}{c}(3) \\
\text { Counterfactual 2015 } \\
\text { using 2000 locations }\end{array}$ \\
\hline White PM2.5 $\mu \mathrm{g} / \mathrm{m}^{3}$ & 12.96 & 8.25 & 8.22 \\
Black PM2.5 $\mathrm{g} / \mathrm{m}^{3}$ & 14.52 & 8.79 & 8.89 \\
\hline Black-White Difference & 1.56 & 0.54 & 0.67 \\
\hline Change in B-W Diff & & 1.02 & 0.89 \\
\hline
\end{tabular}

Notes: Rows (1) and (2) of columns (1) and (2) present mean pollution exposure separately for African American and nonHispanic Whites in years 2000 and 2015. Row (3) presents the mean gap in pollution exposure in either each year. Row (4) presents the change in black-white gap between 2000 and 2015. Column (3) presents a counterfactual exercise, whereby we ask what pollution levels would be and by how much the gap would have converged between 2000-2015 if we fixed the population in their 2000 location and assigned the 2015 pollution levels for their respective Census block. Source: 2000 Decennial Census, American Community Survey 2001-2015, and Di et al. (2016). 
Table 3: The Impact of the 2005 Implementation of PM2.5 Standards on PM2.5 levels

\begin{tabular}{|c|c|c|c|c|c|c|c|c|}
\hline & $\begin{array}{c}(1) \\
\text { PM2.5 }\end{array}$ & $\begin{array}{c}(2) \\
\text { PM2.5 }\end{array}$ & $\begin{array}{c}(3) \\
\ln (\mathrm{PM} 2.5)\end{array}$ & $\begin{array}{c}(4) \\
\ln (\mathrm{PM} 2.5)\end{array}$ & $\begin{array}{c}(5) \\
\text { PM2.5 }\end{array}$ & $\begin{array}{c}(6) \\
\text { PM2.5 }\end{array}$ & $\begin{array}{c}(7) \\
\ln (\mathrm{PM} 2.5)\end{array}$ & $\begin{array}{c}(8) \\
\ln (\mathrm{PM} 2.5)\end{array}$ \\
\hline PM2.5 Nonattain $\times$ Post & $\begin{array}{l}-1.230 \\
(0.335)\end{array}$ & $\begin{array}{l}-1.237 \\
(0.334)\end{array}$ & $\begin{array}{l}-0.075 \\
(0.020)\end{array}$ & $\begin{array}{l}-0.076 \\
(0.020)\end{array}$ & $\begin{array}{l}-0.727 \\
(0.080)\end{array}$ & $\begin{array}{l}-0.726 \\
(0.082)\end{array}$ & $\begin{array}{l}-0.036 \\
(0.006)\end{array}$ & $\begin{array}{l}-0.036 \\
(0.006)\end{array}$ \\
\hline PM2.5 Non $\times$ Black $\times$ Post & & $\begin{array}{c}0.149 \\
(0.088)\end{array}$ & & $\begin{array}{c}0.008 \\
(0.007)\end{array}$ & & $\begin{array}{c}0.048 \\
(0.091)\end{array}$ & & $\begin{array}{c}0.004 \\
(0.005)\end{array}$ \\
\hline Year FE & $\mathrm{X}$ & $\mathrm{X}$ & $\mathrm{X}$ & $\mathrm{X}$ & & & & \\
\hline State-Year FE & & & & & $\mathrm{X}$ & $\mathrm{X}$ & $\mathrm{X}$ & $\mathrm{X}$ \\
\hline County FE & $\mathrm{X}$ & $\mathrm{X}$ & $\mathrm{X}$ & $\mathrm{X}$ & $\mathrm{X}$ & $\mathrm{X}$ & $\mathrm{X}$ & $\mathrm{X}$ \\
\hline Observations & 32360000 & 32360000 & 32360000 & 32360000 & 32360000 & 32360000 & 32360000 & 32360000 \\
\hline
\end{tabular}

Notes: This table presents regression coefficients from 8 separate versions of equation (3), one per column, where the dependent variable consists of PM2.5 or $\ln (\mathrm{PM} 2.5)$ for an individual in a given year. Columns (2), (4), (6), and (8) add an additional interaction for African Americans to test for heterogeneity in regulatory impacts for African Americans. Regressions are weighted by Census survey weights and errors are clustered by commuting zone. Source: 2000

Decennial Census, American Community Survey 2001-2015, EPA NAAQS Greenbook, Di et al. (2016). 
Table 4: Calculating the Effect of CAA Regulations on the Black-White PM2.5 Gap

\begin{tabular}{|c|c|c|c|c|}
\hline $\begin{array}{c}(1) \\
\text { PM2.5 } \\
\text { Quantile } \\
\text { Bin } \\
\end{array}$ & $\begin{array}{c}(2) \\
\text { Actual } \\
\text { PM2.5 } \\
\text { in } 2005\end{array}$ & $\begin{array}{c}(3) \\
\text { Actual } \\
\text { PM2.5 } \\
\text { in } 2015\end{array}$ & $\begin{array}{l}\text { White Counterfactual } \\
\text { PM2.5 in } 2015 \\
\text { Without CAA }\end{array}$ & $\begin{array}{l}(5) \\
\text { Black Counterfactual } \\
\text { PM2.5 in 2015 } \\
\text { Without CAA } \\
\end{array}$ \\
\hline 5 & 5.32 & 4.34 & 4.37 & 4.36 \\
\hline 10 & 7.87 & 5.63 & 5.69 & 5.63 \\
\hline 15 & 8.91 & 6.25 & 6.18 & 6.24 \\
\hline 20 & 9.65 & 6.72 & 6.62 & 6.62 \\
\hline 25 & 10.33 & 7.11 & 7.03 & 6.88 \\
\hline 30 & 10.90 & 7.45 & 7.56 & 7.17 \\
\hline 35 & 11.42 & 7.75 & 8.12 & 7.64 \\
\hline 40 & 11.90 & 8.01 & 8.67 & 8.23 \\
\hline 45 & 12.34 & 8.24 & 9.28 & 8.92 \\
\hline 50 & 12.73 & 8.44 & 9.89 & 9.65 \\
\hline 55 & 13.09 & 8.65 & 10.39 & 10.43 \\
\hline 60 & 13.44 & 8.84 & 10.57 & 10.73 \\
\hline 65 & 13.80 & 9.03 & 10.68 & 10.93 \\
\hline 70 & 14.15 & 9.22 & 10.75 & 11.09 \\
\hline 75 & 14.51 & 9.42 & 10.71 & 11.00 \\
\hline 80 & 14.91 & 9.67 & 10.80 & 11.17 \\
\hline 85 & 15.27 & 9.98 & 10.93 & 11.43 \\
\hline 90 & 15.72 & 10.49 & 11.41 & 12.27 \\
\hline 95 & 17.01 & 12.21 & 12.46 & 13.48 \\
\hline \multicolumn{5}{|c|}{ Main Counterfactual: Including 2005-2015 Mobility Responses } \\
\hline \multirow{5}{*}{\multicolumn{4}{|c|}{$\begin{array}{l}2005 \text { Actual Black-White Gap: } \\
2015 \text { Counterfactual Black-White Gap: } \\
\text { Counterfactual Change in Black-White Gap: } \\
\text { Actual Change in Black-White Gap: } \\
\text { \% of Actual Gap Attributable to CAA: }\end{array}$}} & 1.20 \\
\hline & & & & 0.97 \\
\hline & & & & -0.23 \\
\hline & & & & -0.59 \\
\hline & & & & $61.2 \%$ \\
\hline \multicolumn{5}{|c|}{ Alternative Counterfactual: Holding Population Fixed in 2005 Locations } \\
\hline \multirow{4}{*}{\multicolumn{4}{|c|}{$\begin{array}{l}2005 \text { Actual Black-White Gap: } \\
2015 \text { Counterfactual Black-White Gap: } \\
\text { Counterfactual Change in Black-White Gap: } \\
\text { Actual Change in Black-White Gap: }\end{array}$}} & 1.20 \\
\hline & & & & 1.16 \\
\hline & & & & -0.04 \\
\hline & & & & -0.59 \\
\hline
\end{tabular}

Notes: This table presents calculations used to explore what fraction of the observed racial convergence in mean PM2.5 levels can be attributed to the regulatory variation embedded into the Clean Air Act's 2005 PM2.5 NAAQS. The top panel describes actual pollution levels within each quantile bin in 2000 and 2015. Columns (3) and (4) use estimates from Figure 10 to calculate what pollution would be in 2015 in the absence of the CAA PM2.5 NAAQS implementation, separately for African Americans and non-Hispanic whites. The second panel computes the counterfactual gap in 2015 in the absence of the CAA NAAQS and the implied 2005-2015 change in the gap. The last panel asks what the change in the black-white gap would have been if people did not move between 2005-2015, and the CAA NAAQS was not implemented. Source: 2000 Decennial Census, American Community Survey 2001-2015, EPA NAAQS Greenbook, Di et al. (2016). 


\section{Appendix A Pollution Decompositions}

\section{Appendix A.1 Oaxaca-Blinder Decomposition of Racial Pollution Gaps}

Assume that for an individual $i$ in group $g \in\{b, w\}$ pollution exposure $P_{g i}$ can be written as a linear function of observed characteristics $\left(X_{g i}\right)$ and an error term $\mu_{g i}$

$$
P_{g i}=\beta_{g} X_{g i}+\mu_{g i}
$$

where $\beta_{g}$ are defined so that $E\left[\mu_{g i} \mid X_{g i}\right]=0$. The difference in expected pollution exposure for blacks and whites can be written as:

$$
P_{b}-P_{w}=\left(X_{b}-X_{w}\right) \beta_{b}+\left(\beta_{b}-\beta_{w}\right) X_{w}
$$

where $P_{g}$ and $X_{g}$ represent mean pollution and mean characteristics for all individuals in group $g$. The first term on the right-hand side of equation (2) is the part of the gap explained by differences in the average observable characteristics of the two groups; namely, how large would the observed pollution gap be if we gave blacks the same mean characteristics as whites? The second term is the part of the mean difference in pollution exposure that is not explained by differences in characteristics; instead it reflect differences in the "returns" to the observable characteristics (that is, the differences in slopes between groups, $\beta_{b}-\beta_{w}$, for each observed characteristic).

The results of this initial decomposition are shown in Appendix Table B2 for the two end points of our sample, 2000 and 2015. The first row shows the predicted difference in pollution exposure obtained from left hand side of equation (5): The gap is $-1.616 \mu \mathrm{g} / \mathrm{m}^{3}$ in 2000 , falling to $-0.544 \mu \mathrm{g} / \mathrm{m}^{3}$ by 2015 . The first panel of Table B2 ("Explained") shows that very little of the racial gap in predicted pollution exposure can be explained by an individual's observable characteristics. While African American households have mean household income more than $\$ 15,000$ less than non-Hispanic whites (see Appendix Table B1), these differences in income explain almost none of the observed differences in pollution exposure. In fact, almost none of the observed individual or household characteristics are able to explain any portion of the observed difference in pollution exposure. Only 4.8 percent of the gap $(-0.078 /-1.616)$ is explained by differences in income, age, schooling, children, gender, and/or homeownership. In 2015, differences in these characteristics between blacks and whites are able to explain only 8 percent $(-0.044 /-0.544)$ of the gap in pollution exposure between black and whites. ${ }^{18}$ Hence, differential racial exposure to pollution cannot be explained simply by the fact that African Americans are more disadvantaged in terms of measured characteristics on average than non-Hispanic whites.

The second panel of Table B2 ("Unexplained") shows that the bulk of the racial gap in pollution exposure instead reflects racial differences in the "returns" to observed characteristics and/or differences in unmeasured characteristics. In particular, differences in the coefficients on age and education explain a significant portion of the gap in both 2000 and 2015.

\section{Appendix A.2 Decompositions Using Recentered Influence Functions (RIF)}

While the previous section explored differences in mean outcomes between blacks and whites, it is also possible to decompose other parts of the pollution distribution (e.g., the 10th or 90th percentiles of the white and black pollution distributions). Are observable characteristics able to explain more of the difference in outcomes at the 90th percentiles? What about the 10th percentiles? Recent advances in quantile regression allow us to decompose differences in quantiles of the unconditional pollution distribution using recentered

\footnotetext{
${ }^{18}$ We have experimented with a range of more flexible functional forms for all the control variables, and the qualitative results are nearly identical when including higher order polynomials and/or more flexible dummy variable transformations of the observed continuous variables.
} 
influence functions (RIF) (Firpo, Fortin, and Lemieux, 2009). The basic idea is to transform the problem by considering a covariate's influence on population shares rather than quantiles. By estimating how a covariate (e.g., income) affects the share of the population below various pollution thresholds, we can identify the marginal effect of income on the cumulative distribution function ( $\mathrm{CDF}$ ) of pollution. We can then invert the impact of income on the CDF of pollution to estimate the impact on a pollution quantile. The RIF regression approach proposed by Firpo, Fortin, and Lemieux (2009) performs this inversion using a local linear approximation to the counterfactual CDF, rescaling the marginal effect of each covariate on the share above a pollution cutoff by the probability density of pollution at that cutoff.

In practice, RIF regression requires first transforming the outcome variable, PM2.5 pollution, using a recentered influence function before projecting this transformation on the explanatory variables of interest. RIF-regression methods provide a simple way of performing decompositions for any distributional statistic for which an "influence function" can be computed.

Firpo, Fortin, and Lemieux (2009) consider the following model of pollution P:

$$
P=h(X, \epsilon)
$$

where $X$ represents the set of independent, explanatory variables and $\epsilon$ is the scalar unobserved error term. The unconditional partial effect is defined as the shift in the distribution of a variable $X$ on the distributional statistic $v\left(F_{P}\right)$, which can be expressed as

$$
\int \frac{d E[\operatorname{RIF}(P, v) \mid X=x]}{d x} d F(x)
$$

where $\operatorname{RIF}(P, v)$ is the recentered influence function. When the distributional statistic $v$ is the $\tau$ th quantile function $q_{t}=\inf _{q}\left\{q: F_{P}(q) \geq \tau\right\}$ the $\operatorname{RIF}\left(P, q_{\tau}\right)$ can be represented as:

$$
\operatorname{RIF}\left(P, q_{\tau}\right)=q_{\tau}+\frac{\tau-1\left\{p \leq q_{\tau}\right\}}{f_{P}\left(q_{\tau}\right)},
$$

where $f_{P}\left(q_{\tau}\right)$ is the density function of pollution $P$ evaluated at quantile $q_{\tau}$.

The relevant property of a recentered influence function is that its expectation equals the distributional statistic of interest. For quantile $\tau$ denoted $Q_{\tau}$, the quantile $\operatorname{RIF}$ is given by $\operatorname{RIF}\left(p, Q_{\tau}\right)=Q_{\tau}+\frac{\tau-\mathbf{1}\left(p<Q_{\tau}\right)}{f_{p}\left(Q_{\tau}\right)}$ and taking expectations verifies $E\left[R I F\left(p, Q_{\tau}\right)\right]=Q_{\tau}$. Since the mean of the RIF is equal to the quantile, we can use the law of iterated expectations to decompose each unconditional quantile, as Oaxaca (1973) and Blinder (1973) do when they decompose the mean.

Firpo, Fortin, and Lemieux (2009) show that a regression of the RIF on covariates yields the approximate effect of the covariates on the distributional statistic of interest (applied to the unconditional distribution). As we show in the text, this feature of RIF regressions provides a natural bridge to exploring how treatment effects (e.g., the effects of the CAA PM2.5 regulations on county-year pollution levels) map into the unconditional distribution of pollution.

Appendix Table B3 shows the results of decompositions of the 10th, 50th, and 90th percentiles of the pollution distributions for non-Hispanic whites and African Americans using re-centered influence functions. The first three columns show the estimates for 2000, while the last three columns show the estimates for 2015. Both sets of estimates indicate larger gaps at the 10th percentile than at the 90th percentile. These patterns of quantile differences can largely be explained by recognizing that both non-Hispanic whites and African American live in large cities with high levels of air pollution (i.e. the 90th percentiles of their respective pollution distributions are somewhat similar); whereas rural locations, that also tend to be the least polluted parts of the United States, are disproportionately white, leading to larger gaps in the 10th percentiles of the respective race-specific pollution distributions. As in the Oaxaca-Blinder decompositions, these breakdowns indicate that relatively little of the predicted differences in exposure can be explained by 
differences in individual and household level characteristics. By 2015, the racial gap in the 90th percentile of exposure has narrowed significantly, and, for the first time, most of the gap can be accounted for by differences in observable characteristics. For the most part, however, the quantile decompositions present a pattern similar to the original mean decompositions; black-white differences in individual or household-level characteristics explain very little of the black-white difference in PM2.5 pollution exposure, especially in earlier years.

\section{Appendix A.3 People versus Places: Decomposing the Role of Population Shifts in Changing the Pollution Gap}

We consider an alternative mobility decomposition in order the further explore the role of reallocation of population shares within racial groups over time. We consider pollution exposure $(\Omega)$ as the population share (denoted by $s_{i t}$ ) weighted average of tract $i$ level pollution in year $t \omega_{i t}$. We rely on the following definition of nationwide pollution exposure in year $t \Omega_{t}=\sum_{i} s_{i t} \omega_{i t}$, which corresponds to the share weighted average of Census tract pollution exposure over all $i$ tracts. This differs from the unweighted average of Census tract pollution exposure in a given year $\overline{\omega_{t}}=\frac{1}{N_{t}} \sum_{i} \omega_{i t}$.

We decompose this nationwide pollution term into unweighted tract-level pollution and the covariance between pollution and tract-level population shares. The same decomposition can be applied by race group $\phi$, which can inform us whether the observed pollution changes are driven mostly by improvements in average Census tracts versus shifts in race-specific population shares across Census tracts over time. Denote the population share of each race group as $s(\phi)_{t}=\sum_{i \in \phi} s_{i t}$. Likewise, denote race-specific pollution is $\Omega_{t}(\phi)$, while the average tract-level pollution within a race group is $\bar{\omega}_{t}(\phi)$ Then we can write nationwide pollution exposure as a weighted average of the race-specific components

$$
\begin{gathered}
\Omega_{t}=\sum_{\phi \in b, w} s_{t}(\phi)\left(\bar{\omega}_{t}(\phi)+\sum_{i \in \phi}\left(\omega_{i t}-\bar{\omega}_{t}(\phi)\right)\left(s_{i t}(\phi)-\bar{s}_{t}(\phi)\right)\right) . \\
=\sum_{\phi \in b, w} s_{t}(\phi)\left(\bar{\omega}_{t}(\phi)+\Gamma_{t}(\phi)\right)
\end{gathered}
$$

where $\Gamma_{t}(\phi)$ reflects the covariance between population shares and pollution levels for a respective race group. If African Americans are more concentrated in Census tracts with high pollution levels, this term will be positive for African Americans.

This equation allows us to explain changes in nationwide pollution, through (i) changes in the average pollution of black and white Census tracts $\left(\bar{\omega}_{t}(\phi)\right)$, and (ii) changes in the covariance between population shares and pollution, separately for both blacks and whites $\left(\Gamma_{t}(\phi)\right)$.

We perform this decomposition year by year to better understand the dynamics of this covariance term; if the covariance is falling over time, this would suggest that African Americans were becoming less concentrated in neighborhoods with the worst air quality. If the covariance term were relatively constant over time, the observed improvement in air quality for African Americans is primarily the result of the average African American Census tract getting cleaner.

Appendix Figure B1 shows the results of implementing the decomposition in equation (4) year-by-year, separately for non-Hispanic whites and African Americans. Appendix Table B5 similarly decomposes the 2000-2015 difference in PM2.5 exposure. Figure B1a shows that there is little change in the covariance between air pollution levels and share African American in a Census tract. However, over time, the negative relationship between pollution and non-Hispanic white population shares weakens.

Figure B1b shows that for African Americans, there is virtually a one to one relationship between average individual exposure and the unweighted mean Census tract pollution level, consistent with the flat trend in 
the covariances in Figure B1a. Hence, among African Americans, virtually all of the reduction in pollution exposure can be accounted for by the average African American tract cleaning up, rather than by relocation of African Americans to relatively cleaner tracts. Formally, Column (2) of Table B5 suggests 93\% of the 20002015 improvement in air quality for African Americans can be explained by changes in the average African American tract. The remaining seven percent can be explained by a weakening of the covariance between African American population shares and pollution exposure. Figure B1c shows that the average white pollution exposure is slightly lower than average tract-level exposure, indicating that whites live in cleaner tracts. However, this gap narrows over time, consistent with the trend in covariances shown in Figure B1a. Overall then, this decomposition indicates that a small part of the gap between African Americans and non-Hispanic whites can be accounted for by whites becoming less concentrated in the relatively cleanest neighborhoods, but that most of the relative air quality improvement for African Americans reflects clean ups within tracts rather than relative shifts in black-white population shares to cleaner or dirtier tracts. 


\section{Appendix B Appendix Tables and Figures}

Figure B1: Individual vs. Tract-Level Exposure and Covariance Between Race Share and Air Quality

(a) Tract PM2.5 and Population Share Covariances

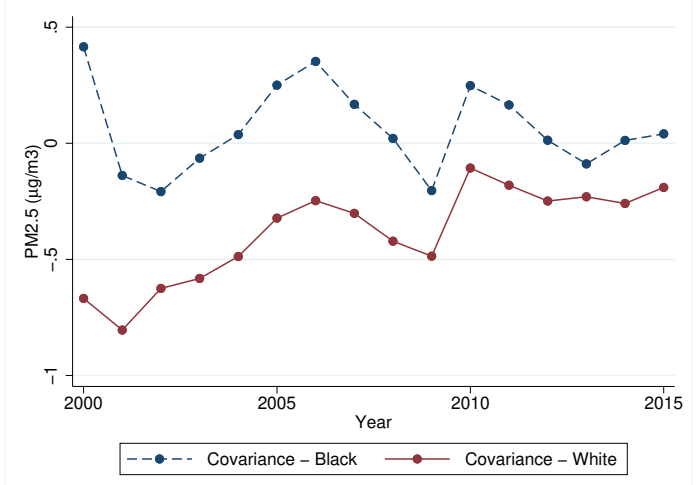

(b) Individual and Tract Average PM2.5 Exposure: African Americans

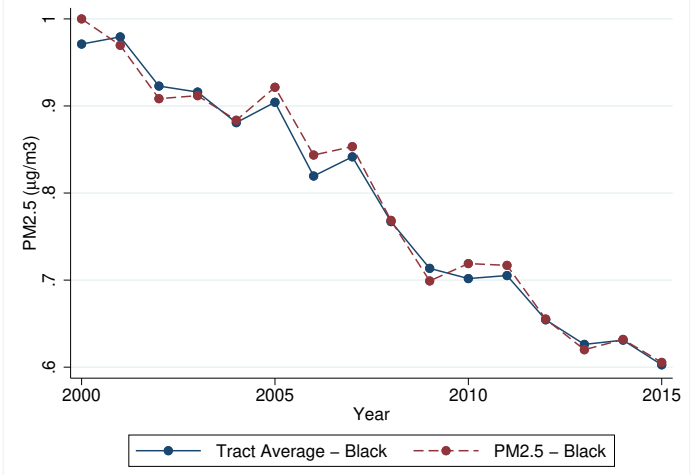

(c) Individual and Tract Average PM2.5 Exposure: non-Hispanic White

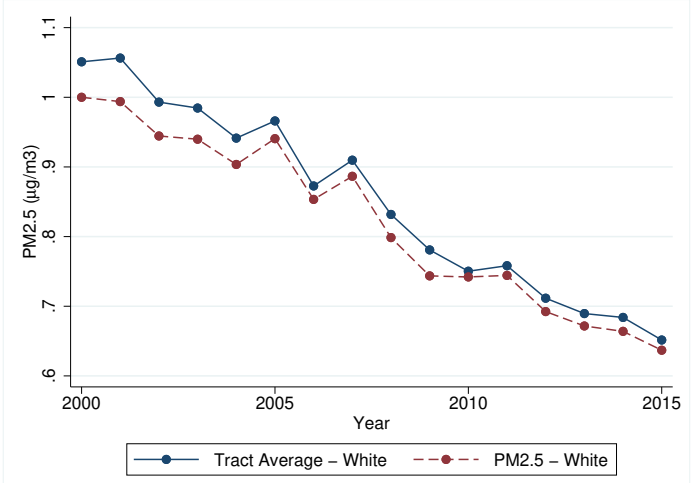

Notes: These figures present results from decomposing average PM2.5 exposure into the unweighted average Census tract exposure for each race group and the assortative relationship between race-specific population shares and pollution levels. Figure (a) presents the year-by-year covariance between race-specific population shares and pollution levels, separately by race. Figure (b) plots the population-weighted trend in PM2.5 exposure for African Americans (dashed line) and the trend in unweighted Census tract exposure for African Americans (solid line). Figure (c) replicates Figure (b) for Non-Hispanic whites. See text for details. Source: 2000 Decennial Census, American Community Survey 2001-2015, and Di et al. (2016). 
Figure B2: Race-Specific RIF-Quantile Treatment Effects of the 2005 CAA PM2.5 NAAQS Implementation

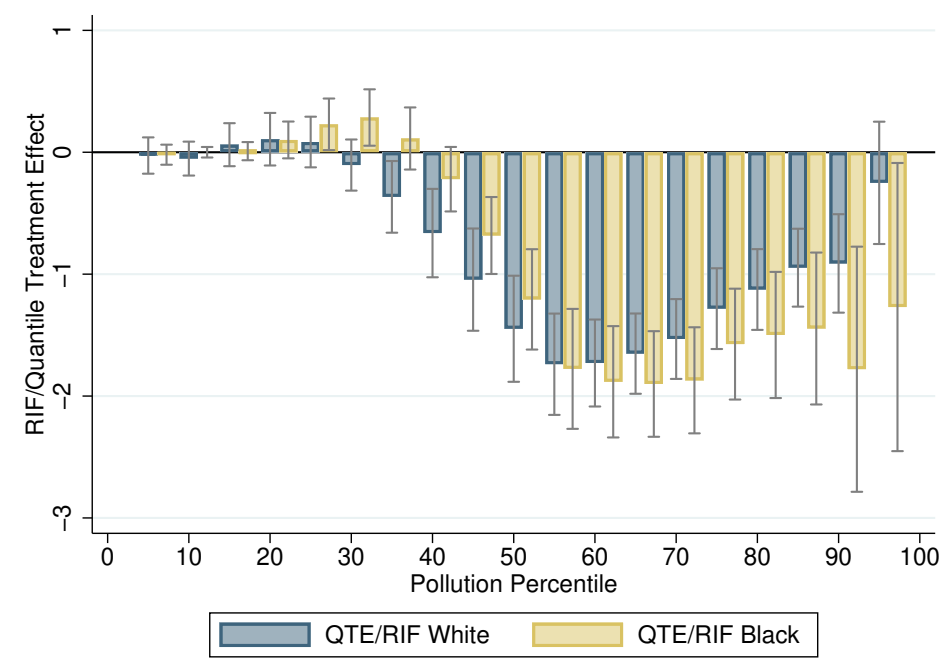

Notes: This figure reproduces Figure 10, including confidence intervals for the regression coefficients. The figure plots the regression coefficient $\hat{\beta}$ from 38 separate versions of equation (3), 19 regressions for each race, where the dependent variable consists of the RIF-Quantile transformation of the respective PM2.5 vigintile (indicated by the x-axis). The regression model controls for county fixed effects and state-by-year fixed effects. The solid gray lines represent 95\% confidence intervals. Regressions are weighted by Census survey weights and errors are clustered by commuting zone. Source: 2000 Decennial Census, American Community Survey 2001-2015, EPA NAAQS Greenbook, Di et al. (2016).

Figure B3: 2005-2015 Change in Population Plotted Against Quantile Treatment Effects

(a) African Americans

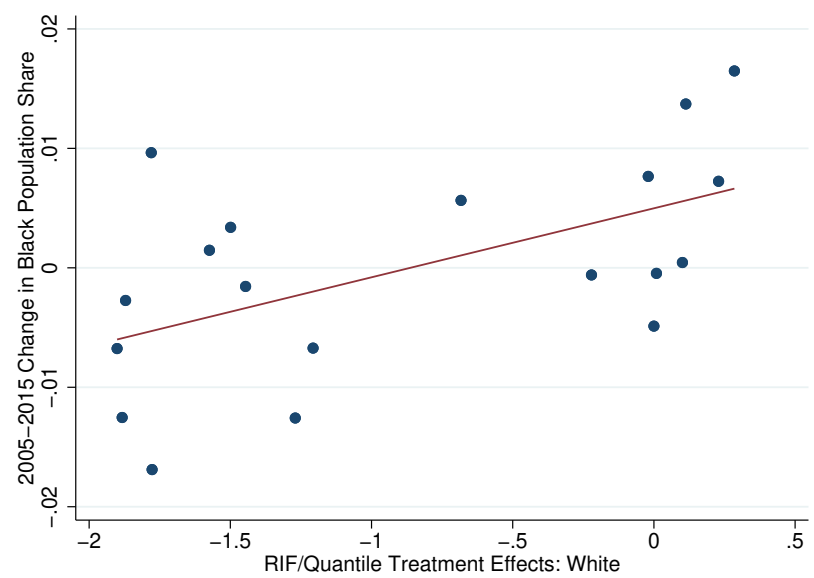

(b) Non-Hispanic White

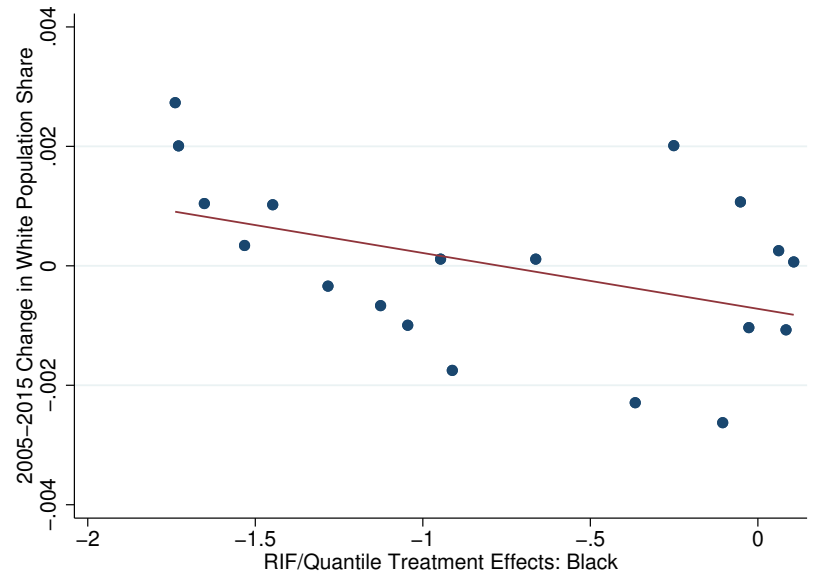

Notes: Figure B3a plots the within-quantile change in the black population share between 2005 and 2015 against the RIFquantile treatment effects for blacks in the respective quantile (i.e. taken from Figure 10). Figure B3b repeats this exercise for non-Hispanic whites. An observation corresponds to a particular quantile bin. Source: 2000 Decennial Census, American Community Survey 2001-2015, and Di et al. (2016). 
Table B1: Summary Statistics by Race, Overall, and Sub-Periods

\begin{tabular}{|c|c|c|c|c|c|c|c|c|}
\hline & $(1)$ & $(2)$ & $(3)$ & & $(5)$ & $(6)$ & \multirow{3}{*}{$\begin{array}{c}(7) \\
\text { Mean Diff. } \\
(5)-(3)\end{array}$} & \multirow{3}{*}{$\begin{array}{c}(8) \\
\text { p-value }\end{array}$} \\
\hline & \multicolumn{2}{|c|}{ Overall } & \multicolumn{2}{|c|}{ African-American } & \multicolumn{2}{|c|}{ Non-Hispanic White } & & \\
\hline & Mean & Std. Dev. & Mean & Std. Dev. & Mean & Std. Dev. & & \\
\hline & \multicolumn{8}{|c|}{ Panel A: Individual Characteristics } \\
\hline Age & 40.010 & 8.573 & 39.410 & 8.536 & 40.100 & 8.575 & 0.687 & $(0.000)$ \\
\hline Years of School & 13.650 & 2.650 & 13.130 & 2.405 & 13.720 & 2.674 & 0.587 & $(0.000)$ \\
\hline Sex $(1=$ Female $)$ & 0.514 & 0.500 & 0.549 & 0.498 & 0.509 & 0.500 & -0.041 & $(0.000)$ \\
\hline Homeowner & 0.703 & 0.457 & 0.486 & 0.500 & 0.733 & 0.443 & 0.247 & $(0.000)$ \\
\hline Number of Children & 1.070 & 1.213 & 1.039 & 1.267 & 1.074 & 1.206 & 0.035 & $(0.000)$ \\
\hline Income & 48130 & 51590 & 34300 & 34630 & 50070 & 53250 & 15760 & $(0.000)$ \\
\hline Bottom Income Quintile & 0.200 & 0.400 & 0.264 & 0.441 & 0.191 & 0.393 & -0.073 & $(0.000)$ \\
\hline Top Income Quintile & 0.200 & 0.400 & 0.106 & 0.307 & 0.213 & 0.410 & 0.108 & $(0.000)$ \\
\hline PM2.5 (Satellite, Block) & 10.770 & 2.980 & 11.460 & 2.748 & 10.680 & 2.999 & -0.780 & $(0.000)$ \\
\hline PM2.5 (Satellite, County) & 10.770 & 2.812 & 11.390 & 2.608 & 10.680 & 2.829 & -0.705 & $(0.000)$ \\
\hline \multirow[t]{2}{*}{ PM2.5 (EPA Monitors, County) } & 11.460 & 2.948 & 12.040 & 2.781 & 11.360 & 2.964 & -0.679 & $(0.000)$ \\
\hline & \multicolumn{8}{|c|}{ Panel B: Census Tract Characteristics in 2000} \\
\hline African American & 0.123 & 0.131 & 0.262 & 0.175 & 0.103 & 0.110 & -0.158 & $(0.000)$ \\
\hline Public Assistance Income & 34.04 & 39.98 & 34.35 & 40.89 & 33.99 & 39.85 & -0.352 & $(0.902)$ \\
\hline Income & 48130 & 12920 & 47660 & 12780 & 48200 & 12930 & 540 & $(0.392)$ \\
\hline Years of Schooling & 13.640 & 0.708 & 13.680 & 0.683 & 13.640 & 0.712 & -0.035 & $(0.276)$ \\
\hline$\%$ Worked Last Year & 0.834 & 0.047 & 0.828 & 0.046 & 0.835 & 0.047 & 0.007 & $(0.012)$ \\
\hline Housing Value & 292500 & 183000 & 292200 & 178900 & 292500 & 183500 & 299 & $(0.980)$ \\
\hline Housing Rent & 1096 & 317 & 1116 & 294 & 1094 & 320 & -22.220 & $(0.203)$ \\
\hline$\%$ Home Owners & 0.703 & 0.111 & 0.657 & 0.120 & 0.709 & 0.108 & 0.053 & $(0.000)$ \\
\hline \% Single Family Residence & 0.831 & 0.051 & 0.822 & 0.049 & 0.833 & 0.051 & 0.011 & $(0.000)$ \\
\hline$\%$ in Urban County & 0.992 & 0.089 & 0.997 & 0.057 & 0.991 & 0.092 & -0.005 & $(0.000)$ \\
\hline \multirow[t]{2}{*}{ \% Manufacturing Emp. } & 0.133 & 0.095 & 0.115 & 0.086 & 0.136 & 0.096 & 0.022 & $(0.000)$ \\
\hline & \multicolumn{8}{|c|}{ Panel C: County-Level Characteristics in 2000} \\
\hline African American & 0.129 & 0.232 & 0.556 & 0.320 & 0.069 & 0.134 & -0.487 & $(0.000)$ \\
\hline Welfare Income & 30.50 & 135.80 & 51.71 & 205.90 & 27.53 & 122.60 & -24.180 & $(0.000)$ \\
\hline Years of School & 13.590 & 1.409 & 13.150 & 1.305 & 13.650 & 1.412 & 0.496 & $(0.000)$ \\
\hline Single Family Residence & 0.824 & 0.163 & 0.792 & 0.186 & 0.829 & 0.159 & 0.037 & $(0.000)$ \\
\hline Teen Pregnancy & -0.042 & 0.061 & -0.063 & 0.074 & -0.039 & 0.058 & 0.024 & $(0.000)$ \\
\hline Home Ownership & 0.720 & 0.204 & 0.603 & 0.236 & 0.737 & 0.194 & 0.134 & $(0.000)$ \\
\hline
\end{tabular}

Notes: This table presents summary statistics for individual and neighborhood characteristics for our main analysis sample. Source: 2000 Decennial Census, American Community Survey 2001-2015, and Di et al. (2016). 
Table B2: Decomposition of Mean Differences in Pollution Exposure into Components Explained by Differences in Individual Characteristics and due to Differences in "Returns" to Characteristics

\begin{tabular}{lcc}
\hline & $(1)$ & $(2)$ \\
& Year 2000 & Year 2015 \\
\hline Predicted difference & -1.616 & -0.544 \\
\hline \multicolumn{3}{c}{ Panel A: Explained Gap } \\
Income & -0.001 & 0.000 \\
Age & -0.009 & -0.002 \\
Schooling & -0.011 & -0.010 \\
Kids & 0.003 & 0.001 \\
Gender & 0.000 & 0.000 \\
Homeowner & -0.061 & -0.033 \\
Total & -0.078 & -0.044 \\
\hline \multicolumn{1}{c}{ Panel B: Unexplained Gap } \\
Income & 0.040 & 0.013 \\
Age & -0.412 & -0.251 \\
Schooling & -0.419 & -0.456 \\
Kids & 0.018 & 0.049 \\
Gender & -0.009 & -0.002 \\
Homeowner & -0.002 & 0.000 \\
Constant & -0.755 & 0.146 \\
Total & -1.537 & -0.500 \\
\hline N & 10550000 & 1185000 \\
\hline
\end{tabular}

Notes: This table plots the results from an Oaxaca-Blinder decomposition of mean differences in PM2.5 exposure between African-Americans and non-Hispanic whites. Column (1) performs this decomposition for the year 2000, whereas column (2) decomposes differences originating in 2015. Panel A displays the amount by which black-white differences in the respective covariates explain the gap in mean PM2.5 exposure between groups. Panel B presents the amount by which black-white differences in the respective coefficient estimates explain the gap in mean PM2.5 exposure between groups. Source: 2000 Decennial Census, American Community Survey 2001-2015, and Di et al. (2016). 
Table B3: Decomposition of Quantile Differences in Pollution Exposure into Components Explained by Differences in Individual Characteristics and due to Differences in "Returns" to Characteristics

\begin{tabular}{|c|c|c|c|c|c|c|}
\hline & (1) & $(2)$ & $(3)$ & (4) & (5) & (6) \\
\hline & \multicolumn{3}{|c|}{ Year 2000} & \multicolumn{3}{|c|}{ Year 2015} \\
\hline & $\begin{array}{c}\text { 10th } \\
\text { Percentile }\end{array}$ & $\begin{array}{c}50 \text { th } \\
\text { Percentile }\end{array}$ & $\begin{array}{c}90 t h \\
\text { Percentile }\end{array}$ & $\begin{array}{c}\text { 10th } \\
\text { Percentile }\end{array}$ & $\begin{array}{c}50 t h \\
\text { Percentile }\end{array}$ & $\begin{array}{c}90 \text { th } \\
\text { Percentile }\end{array}$ \\
\hline Predicted difference & -2.360 & -1.607 & -0.861 & -1.081 & -0.434 & -0.130 \\
\hline $\begin{array}{l}\text { Income } \\
\text { Age } \\
\text { Schooling } \\
\text { Kids } \\
\text { Gender } \\
\text { Homeowner } \\
\text { Total }\end{array}$ & $\begin{array}{c}0.004 \\
-0.015 \\
0.002 \\
0.004 \\
-0.002 \\
-0.041 \\
-0.049\end{array}$ & $\begin{array}{c}-0.003 \\
-0.008 \\
-0.006 \\
0.004 \\
0.001 \\
-0.010 \\
-0.023\end{array}$ & $\begin{array}{c}\text { Panel A: E } \\
-0.001 \\
-0.002 \\
0.001 \\
0.002 \\
0.001 \\
-0.120 \\
-0.119\end{array}$ & $\begin{array}{c}\text { ained Gap } \\
0.001 \\
-0.003 \\
0.003 \\
-0.001 \\
0.0001 \\
-0.034 \\
-0.034\end{array}$ & $\begin{array}{c}0.000 \\
-0.002 \\
-0.001 \\
0.000 \\
0.000 \\
-0.018 \\
-0.019\end{array}$ & $\begin{array}{c}0.001 \\
-0.002 \\
-0.021 \\
0.002 \\
0.000 \\
-0.056 \\
-0.077\end{array}$ \\
\hline $\begin{array}{l}\text { Income } \\
\text { Age } \\
\text { Schooling } \\
\text { Kids } \\
\text { Gender } \\
\text { Homeowner } \\
\text { Constant } \\
\text { Total } \\
\end{array}$ & $\begin{array}{c}0.240 \\
-0.696 \\
0.316 \\
0.045 \\
-0.018 \\
-0.006 \\
-2.191 \\
-2.311 \\
\end{array}$ & $\begin{array}{l}-0.057 \\
-0.352 \\
-0.147 \\
-0.004 \\
-0.007 \\
0.004 \\
-1.020 \\
-1.584 \\
\end{array}$ & $\begin{array}{c}\text { Panel B: Ul } \\
0.011 \\
0.036 \\
-0.981 \\
0.013 \\
-0.002 \\
-0.000 \\
0.181 \\
-0.742 \\
\end{array}$ & $\begin{array}{c}\text { plained Gap } \\
0.016 \\
-0.399 \\
-0.114 \\
0.040 \\
-0.007 \\
0.001 \\
-0.585 \\
-1.047 \\
\end{array}$ & $\begin{array}{c}-0.008 \\
-0.205 \\
-0.263 \\
0.034 \\
-0.002 \\
-0.003 \\
0.031 \\
-0.415 \\
\end{array}$ & $\begin{array}{c}0.046 \\
-0.262 \\
-0.696 \\
0.059 \\
0.001 \\
0.003 \\
0.795 \\
-0.053 \\
\end{array}$ \\
\hline $\mathrm{N}$ & 10550000 & 10550000 & 10550000 & 1185000 & 1185000 & 1185000 \\
\hline
\end{tabular}

Notes: This table plots the results from six RIF decompositions of quantile differences in PM2.5 exposure between AfricanAmericans and non-Hispanic whites, where quantiles are indicate in the column headings. Columns (1)-(3) perform this decomposition for the year 2000, whereas columns (4)-(6) decompose differences originating in 2015. Panel A displays the amount by which black-white differences in the respective covariates explain the gap in quantile PM2.5 exposure between groups. Panel B presents the amount by which black-white differences in the respective coefficient estimates explain the gap in quantile PM2.5 exposure between groups. Source: 2000 Decennial Census, American Community Survey 2001-2015, and Di et al. (2016). 
Table B4: Oaxaca-Blinder Decomposition, Census Tract Characteristics

\begin{tabular}{|c|c|c|}
\hline & $\begin{array}{c}(1) \\
\text { Year } 2000 \\
\end{array}$ & $\begin{array}{c}(2) \\
\text { Year } 2015 \\
\end{array}$ \\
\hline Predicted difference & -1.617 & -0.772 \\
\hline \multicolumn{3}{|c|}{ Panel A: Explained Gap } \\
\hline Income & 0.000 & 0.000 \\
\hline Age & -0.008 & -0.003 \\
\hline Schooling & -0.002 & -0.003 \\
\hline Kids & 0.002 & 0.001 \\
\hline Gender & -0.001 & 0.000 \\
\hline Homeowner & 0.001 & 0.019 \\
\hline \multicolumn{3}{|l|}{ Neighborhood/Tract } \\
\hline Tract $\%$ Black & -2.311 & -0.502 \\
\hline Tract Public Assistance Income & -0.037 & -0.007 \\
\hline Tract Years of Schooling & -0.034 & -0.021 \\
\hline Tract \% Single Family Residence & 0.280 & 0.010 \\
\hline Tract Teen Pregnancy Rate & 0.032 & -0.002 \\
\hline Tract Home Ownership Rate & -0.266 & -0.116 \\
\hline Total & -2.344 & -1.032 \\
\hline \multicolumn{3}{|c|}{ Panel B: Unexplained Gap } \\
\hline Income & -0.052 & 0.028 \\
\hline Age & -0.221 & -0.218 \\
\hline Schooling & -0.359 & -0.292 \\
\hline Kids & 0.039 & 0.047 \\
\hline Gender & -0.003 & -0.003 \\
\hline Homeowner & 0.002 & -0.004 \\
\hline \multicolumn{3}{|l|}{ Neighborhood/Tract } \\
\hline Tract \% Black & 1.687 & 0.185 \\
\hline Tract Public Assistance Income & -0.190 & 0.010 \\
\hline Tract Years of Schooling & -3.274 & -1.046 \\
\hline Tract \% Single Family Residence & 1.692 & 0.139 \\
\hline Tract Teen Pregnancy Rate & -0.074 & -0.015 \\
\hline Tract Home Ownership Rate & -0.875 & -0.403 \\
\hline Constant & 2.356 & 0.866 \\
\hline Total & 0.727 & 0.260 \\
\hline $\mathrm{N}$ & 10550000 & 1185000 \\
\hline
\end{tabular}

Notes: This table plots the results from two Oaxaca-Blinder decompositions of mean differences in PM2.5 exposure between African-Americans and non-Hispanic whites. Column (1) performs this decomposition for the year 2000, whereas column (2) decomposes differences originating in 2015. Panel A displays the amount by which black-white differences in the respective covariates explain the gap in mean PM2.5 exposure between groups. Panel B presents the amount by which black-white differences in the respective coefficient estimates explain the gap in mean PM2.5 exposure between groups. Source: 2000 Decennial Census, American Community Survey 2001-2015, and Di et al. (2016). 
Table B5: Decompositions of PM2.5 Exposure Changes 2000-2015 by Race

\begin{tabular}{lcc}
\hline & $\begin{array}{c}(1) \\
\text { Non-Hispanic White }\end{array}$ & African American \\
\hline Average PM2.5 Change by Race: $2000-2015(\Omega(\phi))$ & -4.716 & -5.728 \\
Decomposition: & & \\
$\quad$ Unweighted Average Tract Change: $2000-2015(\bar{\omega}(\phi))$ & $-5.176(110 \%)$ & $-5.349(93.3 \%)$ \\
$\quad$ Change in Covariance 2000-2015 $\left(\Gamma^{O P}(\phi)\right)$ & $0.478(-0.10 \%)$ & $-0.375(6.6 \%)$ \\
\hline
\end{tabular}

Notes: This table decomposes the average 2000-2015 change in pollution exposure by race into that which can be explained by unweighted Census-tract level changes in PM2.5 versus reallocation of population shares to cleaner/dirtier Census tracts over time. Source: 2000 Decennial Census, American Community Survey 2001-2015, and Di et al. (2016). 